\title{
Prescribing Optimal Nutrition and Physical Activity as "First-Line" Interventions for Best Practice Management of Chronic Low-Grade Inflammation Associated with Osteoarthritis: Evidence Synthesis
}

\author{
Elizabeth Dean ${ }^{1}$ and Rasmus Gormsen Hansen ${ }^{2}$ \\ ${ }^{1}$ Department of Physical Therapy, Faculty of Medicine, University of British Columbia, Vancouver, BC, Canada V6T $1 Z 3$ \\ ${ }^{2}$ Department of Physical Therapy, Ringsted and Slagelse Hospitals, Region Zealand, Denmark \\ Correspondence should be addressed to Elizabeth Dean, elizabeth.dean@ubc.ca
}

Received 7 August 2012; Revised 23 November 2012; Accepted 24 November 2012

Academic Editor: Pierre Youinou

Copyright ( 2012 E. Dean and R. Gormsen Hansen. This is an open access article distributed under the Creative Commons Attribution License, which permits unrestricted use, distribution, and reproduction in any medium, provided the original work is properly cited.

\begin{abstract}
Low-grade inflammation and oxidative stress underlie chronic osteoarthritis. Although best-practice guidelines for osteoarthritis emphasize self-management including weight control and exercise, the role of lifestyle behavior change to address chronic lowgrade inflammation has not been a focus of first-line management. This paper synthesizes the literature that supports the idea in which the Western diet and inactivity are proinflammatory, whereas a plant-based diet and activity are anti-inflammatory, and that low-grade inflammation and oxidative stress underlying osteoarthritis often coexist with lifestyle-related risk factors and conditions. We provide evidence-informed recommendations on how lifestyle behavior change can be integrated into "firstline" osteoarthritis management through teamwork and targeted evidence-based interventions. Healthy living can be exploited to reduce inflammation, oxidative stress, and related pain and disability and improve patients' overall health. This approach aligns with evidence-based best practice and holds the promise of eliminating or reducing chronic low-grade inflammation, attenuating disease progression, reducing weight, maximizing health by minimizing a patient's risk or manifestations of other lifestyle-related conditions hallmarked by chronic low-grade inflammation, and reducing the need for medications and surgery. This approach provides an informed cost effective basis for prevention, potential reversal, and management of signs and symptoms of chronic osteoarthritis and has implications for research paradigms in osteoarthritis.
\end{abstract}

\section{Introduction}

Best practice guidelines for chronic osteoarthritis focus on self-management, that is, weight control and physical activity, and on pharmacological support for inflammation and pain [1-5]. Despite such guidelines, authorities in the field report a lack of efficacy of current treatments and associated adverse effects [6], with some proposing even greater attention to self-management [7]. Further, although low-grade inflammation underlies chronic osteoarthritis comparable to other conditions with significant lifestylerelated components often presenting concurrently with osteoarthritis, this inflammation has not been a focus of best practice guidelines, particularly of its nonpharmacologic management.

To establish the prescription of optimal nutrition and physical activity as "first-line" interventions for low-grade inflammation associated with chronic osteoarthritis, we have synthesized three primary lines of support: (1) the literature that supports that the western diet and inactive lifestyle are proinflammatory, and a plant-based diet and regular physical activity are anti-inflammatory; (2) the literature supporting that low-grade inflammation is common across lifestylerelated conditions including osteoarthritis; and (3) evidenceinformed recommendations for effecting lifestyle behavior change that can be readily integrated by health practitioners 
into "first-line" management. We conclude with implications for clinical practice and research with respect to its paradigm and avenues for future investigation.

\section{Low-Grade Inflammation and Lifestyle}

Human lifestyles have changed dramatically over millennia. With technological and economic advancements in western countries particularly over the past 60 years, lifestyle-related conditions are the leading causes of premature death [13]. With globalization, western diets coupled with inactivity have contributed largely to lifestyle-related conditions which are increasingly prevalent in middle- and low-income countries [14]. Some authorities have not only argued that western diets have contributed to poor chronic health outcomes, but that national food guidelines such as those in the United States have legitimized poor nutrition for several decades further contributing to the pandemic of lifestyle-related conditions [15]. In particular, poor nutritional quality has been reported to contribute to obesity [16], a primary risk factor for osteoarthritis [17], in addition to calorie density.

The factors associated with the typical western lifestyle that impact people's health have been elucidated by crosscultural studies including seminal work related to Mediterranean diet and exercise patterns and Asian lifestyles. The Mediterranean diet known to be health protective is largely plant based, favors olive oil over animal fats, and is high in fiber, vegetables, and fruits [18]. The China study [1922] is a prime example. This comprehensive series of studies has shown the serious health consequences of high consumption of meat, dairy, fat, and refined grains and sugar (proinflammatory), and low consumption of whole grains, vegetables and fruits, and legumes and pulses (antiinflammatory). This unnatural diet for humans contributes to low-grade systemic inflammation and oxidative tissue stress and irritation, placing the immune system in an overactive state, a common denominator of conditions with lifestyle components including arthritis [15]. Both high carbohydrate and high fat consumption contribute to inflammatory and oxidative stress even in healthy people [23]. This effect could accentuate inflammatory conditions such as lowering the threshold for local inflammation in arthritis. Diet-induced weight loss in people who are overweight reduces chronic low-grade inflammation as evidenced by signification reduced C-reactive protein, an inflammation biomarker [24].

In addition, sedentary living and inactivity are hallmarks of western culture. Evidence supports that inactivity is proinflammatory and augments oxidative stress [25], whereas activity when not excessive is anti-inflammatory [26, 27]. More commonly understood about exercise, however, is that inactivity weakens muscles and contributes to joint stress, in addition to reducing stimulation of synovial fluid which cushions the joints and protects the joint spaces [28]. Activity and exercise continue to be primarily recommended and prescribed to people with arthritis to offset these adverse effects. The anti-inflammatory effects of exercise, however, have been well established, and that for maximal antiinflammatory benefit, broad-based training needs to include resistance and aerobic training [26, 27, 29]. Exercise induced analgesia [30] and stiffness associated with osteoarthritis may reflect both its anti-inflammatory and mechanical effects; however, exercise's anti-inflammatory effects are not discussed in established practice guidelines [1-5]. In sum, the western lifestyle is inherently unhealthy, and lifestyles with nonwestern diets and greater activity levels are typically associated with better health outcomes, for example, traditional Asian and Mediterranean lifestyles [18, 31].

Other lifestyle traits common in western culture are also known to be proinflammatory. Smoking, for example, remains prevalent despite some success in recent decades in reducing its prevalence through public health campaigns. The chronic low-grade inflammation associated with smoking $[32,33]$ has been linked with inflammatory states associated with ischemic heart disease [34], rheumatoid arthritis [35], and osteoarthritis [36]. Low-grade inflammation has been associated with chronic sleep deprivation and stress [37-40] which are also common in western cultures. Given the well-documented link between low-grade inflammation and oxidative stress, and sleep deprivation and stress [41], a case can be made for assessing and addressing these in the initial assessment and in first-line management of chronic osteoarthritis. In addition, sleep deprivation and stress are common arthritic complaints secondary to discomfort and pain, lending further support for assessing sleep and stress in people with chronic osteoarthritis and intervening as indicated.

Thus, prescribing healthy living strategies in general as well as optimal nutrition (of which weight loss is an additional benefit) and regular physical activity are warranted as being first-line interventions in clinical practice guidelines for conditions such as osteoarthritis associated with chronic low-grade inflammation. These conditions are described in the next section and often coexist as comorbidities in people with osteoarthritis.

\section{Low-Grade Inflammation and Lifestyle-Related Conditions Including Osteoarthritis}

Figure 1 illustrates the interactive relationship among osteoarthritis, obesity, and physical inactivity. Obesity is an independent risk factor for osteoarthritis [84]. Although the mechanisms for this association are not completely understood, biomechanical loading and metabolic inflammation associated with excess adipose tissue and lipids may have a role. Pain associated with osteoarthritis leads to increasingly less activity and psychosocial and physical disability. Physical inactivity is an independent risk factor for inflammation due to the reduced expression of systemic and cellular anti-inflammatory mediators. Physiologic cyclic loading of cartilage tissue reduces the expression of proinflammatory mediators and decreases cytokine-induced extracellular matrix degradation. Physical inactivity reduces daily energy expenditure thereby promoting weight gain and continuation of the cycle. Emerging evidence indicates that osteoarthritis likely impedes the management of chronic 


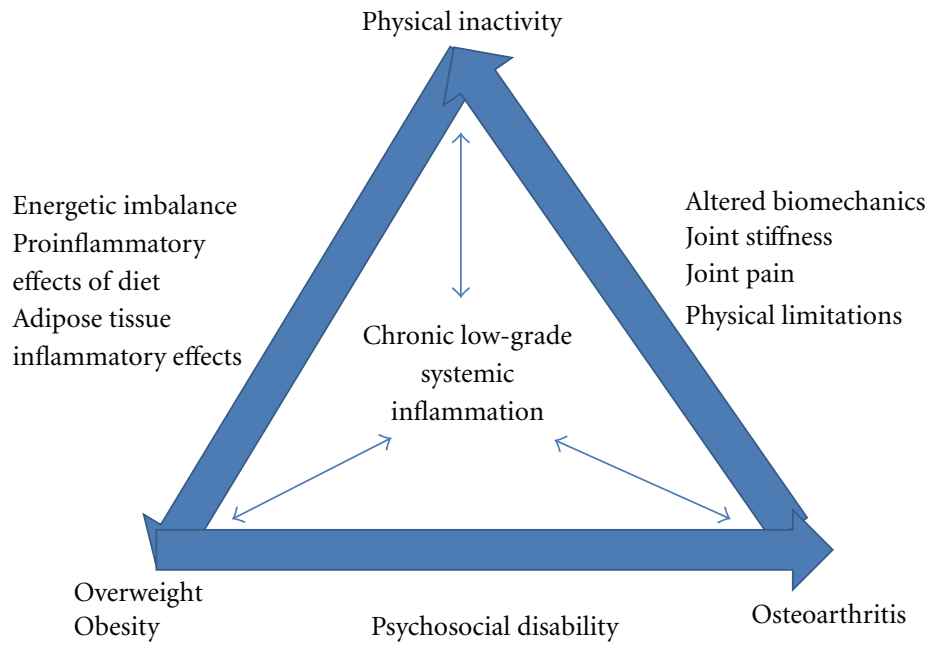

FIGURE 1: Relationships among osteoarthritis, obesity, and physical inactivity and relationship to the etiology of chronic low-grade systemic inflammation. Adapted from [8].

metabolic conditions associated with prolonged negative lifestyle habits such as obesity, type 2 diabetes mellitus, and ischemic heart disease, because of its negative impact on physical activity.

Table 1 shows evidence for chronic low-grade inflammation and oxidative stress in people with osteoarthritis. Multiple comorbidities that share comparable underlying chronic low-grade inflammation and oxidative stress often coexist in individuals with chronic osteoarthritis, Examples of these conditions and synthesis of the evidence appear in Table 2, for example, atherosclerosis, chronic cancer, chronic obstructive lung disease, diabetes, hypertension, insulin resistance and metabolic syndrome, ischemic heart disease, obesity, and stroke. Almost 20 percent of American adults report having physician-diagnosed arthritis, and this is expected to increase over the next two decades [88]. Based on the Behavioral Risk Factor Surveillance System and National Health Interview Survey in the United States, individuals with osteoarthritis have a high incidence of other lifestyle-related conditions with inflammatory components that often present comorbidly with osteoarthritis (see examples in Table 2). Our search strategy used keywords including lifestyle-related conditions, chronic low-grade or chronic systemic inflammation. This synthesis of evidence reflects the literature indexed in established electronic data bases (MEDLINE and PubMed) and primarily published over the past five years. However, in several instances, important related work that was published earlier has been included in this evidence synthesis. The literature extracted represents a breadth of scholarly paradigms including clinical trials, cross-sectional population-based studies, experimental trials based on basic science and models and histological evidence, expert narrative reviews, randomized controlled clinical trials, and systematic reviews.

Although the degree to which the typical western lifestyle explains the prevalence of osteoarthritis is unclear, maximizing healthy living may have the greatest potential for minimizing its risk, its impact, and long-term outcomes including life-long health and wellbeing compared with invasive interventions including drugs and surgery and their related sequelae and side effects.

Overweight is now considered a leading condition associated with marked inflammation followed by arthritis, heart disease, and type 2 diabetes mellitus [89]. The mechanism whereby overweight contributes to inflammation is reported to involve high fat content of the diet [90]. Thus, promoting healthy weight through healthy nutrition in addition to regular physical activity and exercise is critically important to promote a maximally anti-inflammatory systemic environment to offset low-grade inflammation as well as to achieve weight loss.

\section{Integration of Lifestyle Behavior Change into "First-Line" Management}

For lifestyle behavior change to constitute "first-line" management as the literature would support, the health care team overall needs to share this goal and practice in partnership rather than in the conventional siloed care. The three primary health professions excluding, dentistry and pharmacy, include physicians, nurses, and physical therapists. Traditionally, physicians are highly trained in administration of invasive interventions, that is, drugs and surgery. Nurses have assumed a role in patient education over the years along with psychosocial considerations of patient care. Of the established health professions, physical therapy is the leading nonpharmacologic profession that is particularly well positioned to assume such an education role for patients related to healthy lifestyles and exercise [91, 92].

Consistent with the 21st century epidemiological trends, physical therapists are moving toward a model of care based on health (International Classification of Functioning, Disability and Health) [91, 93], which includes initiating and supporting behavior change such as optimal nutrition, weight reduction, reduced sedentary activity, and increased 


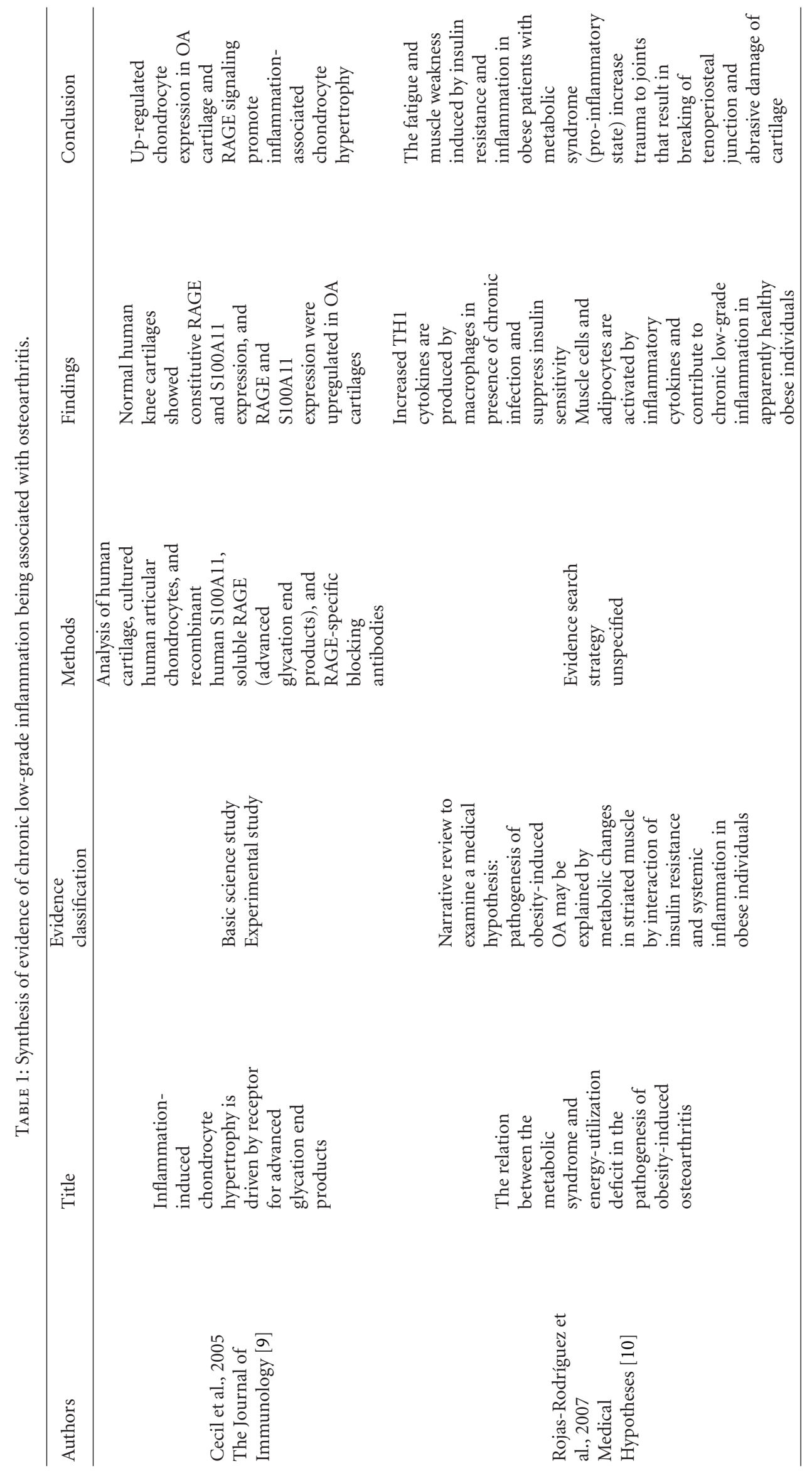




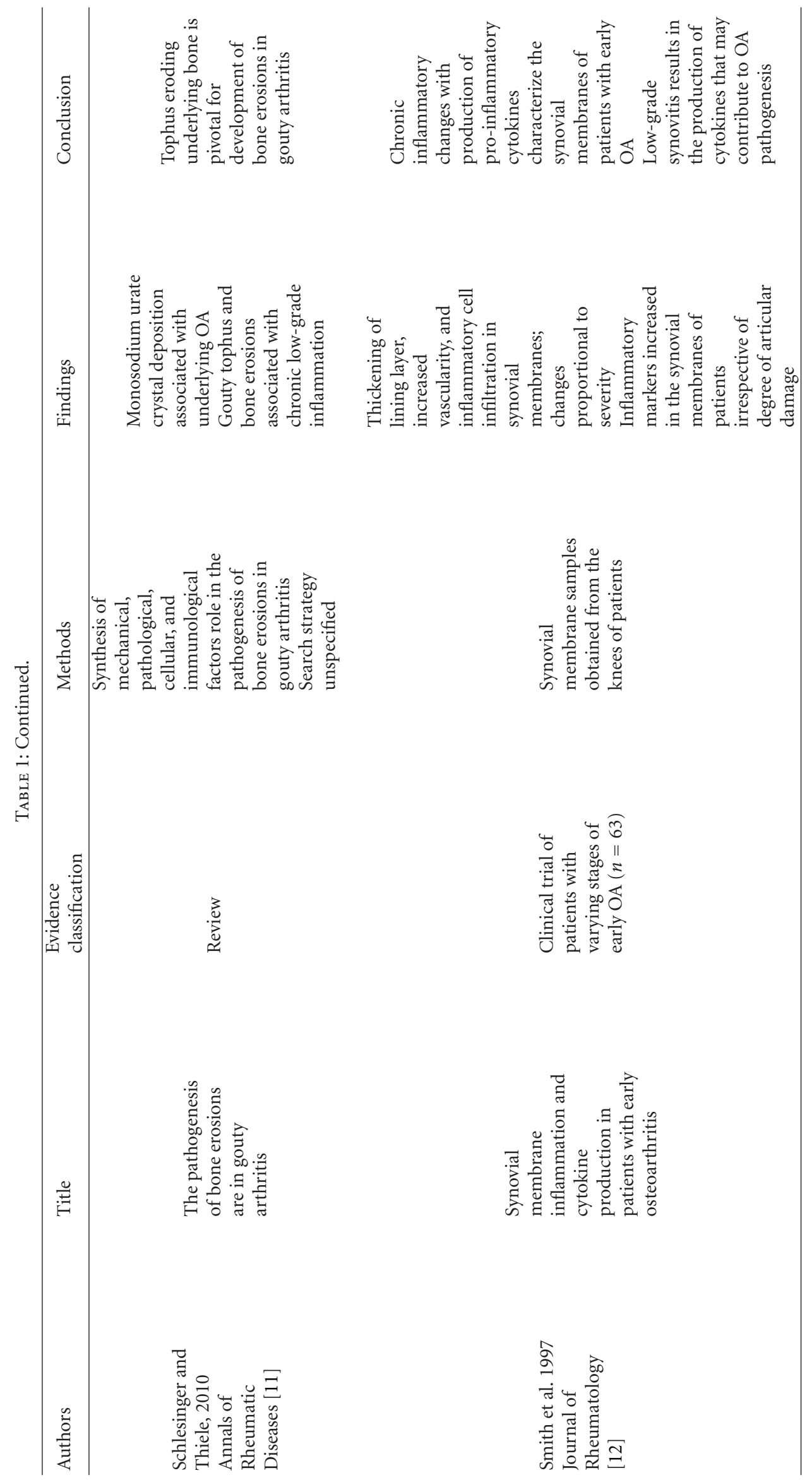




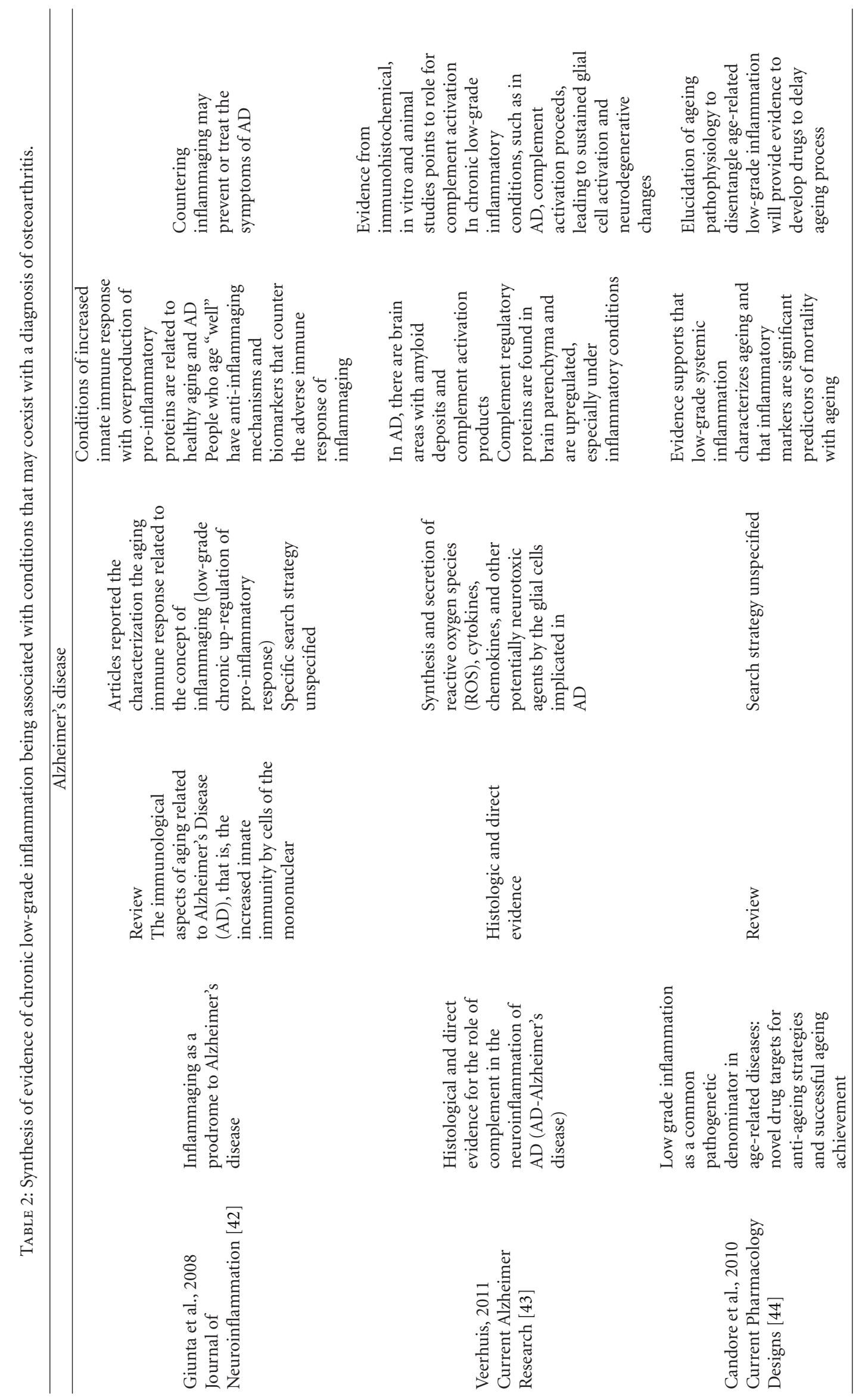




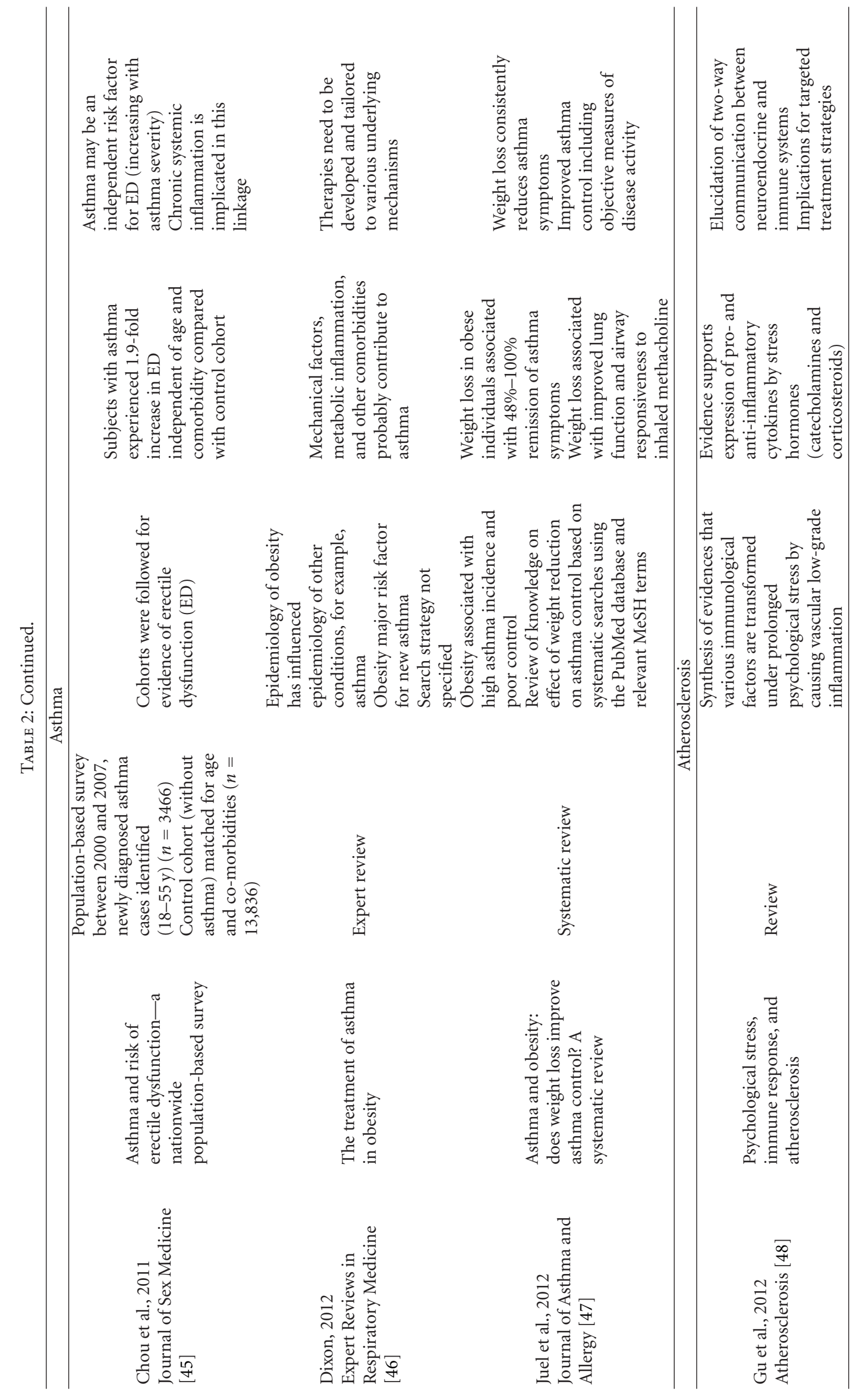



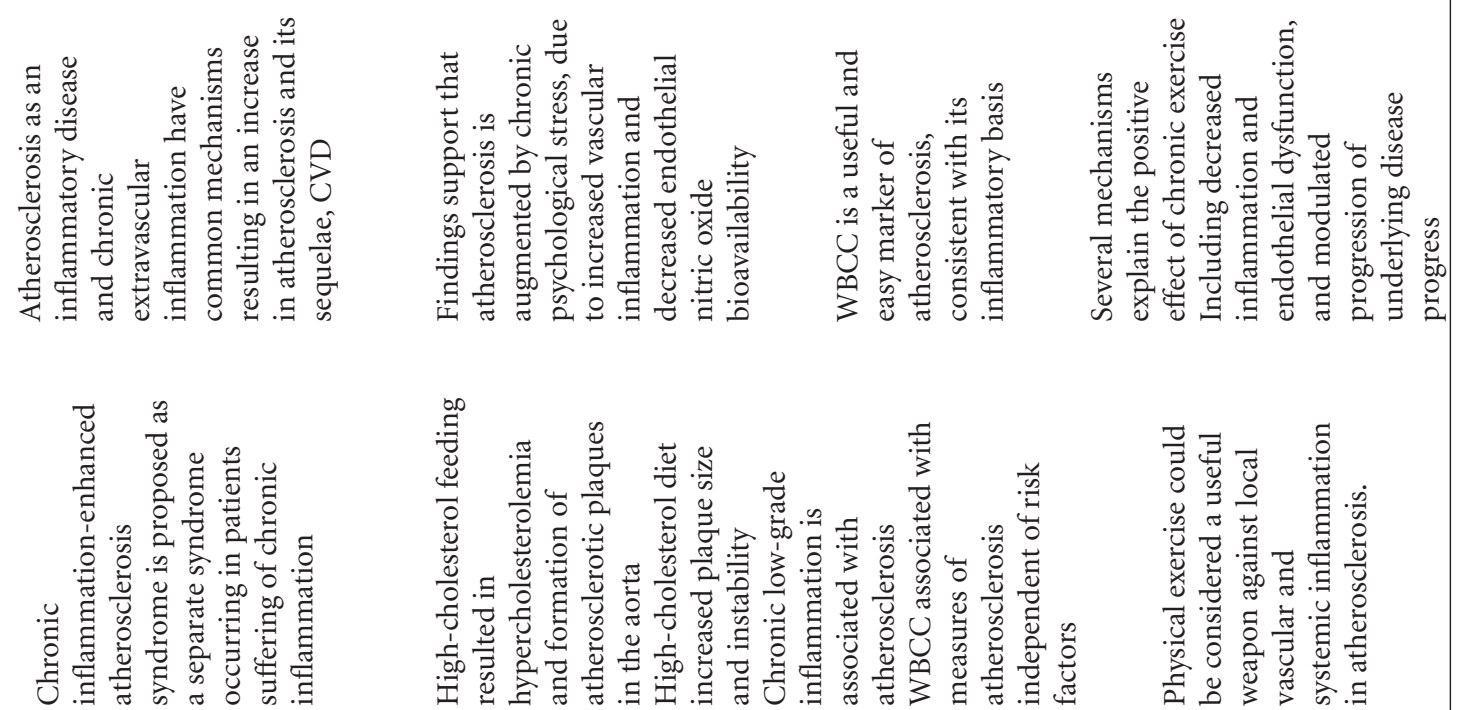

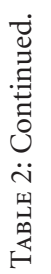

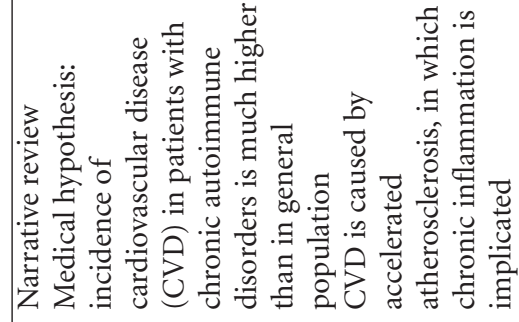

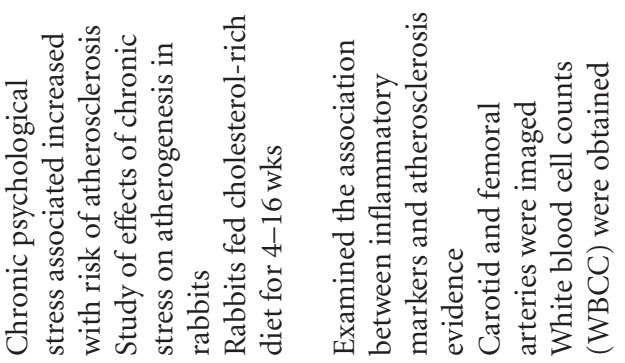
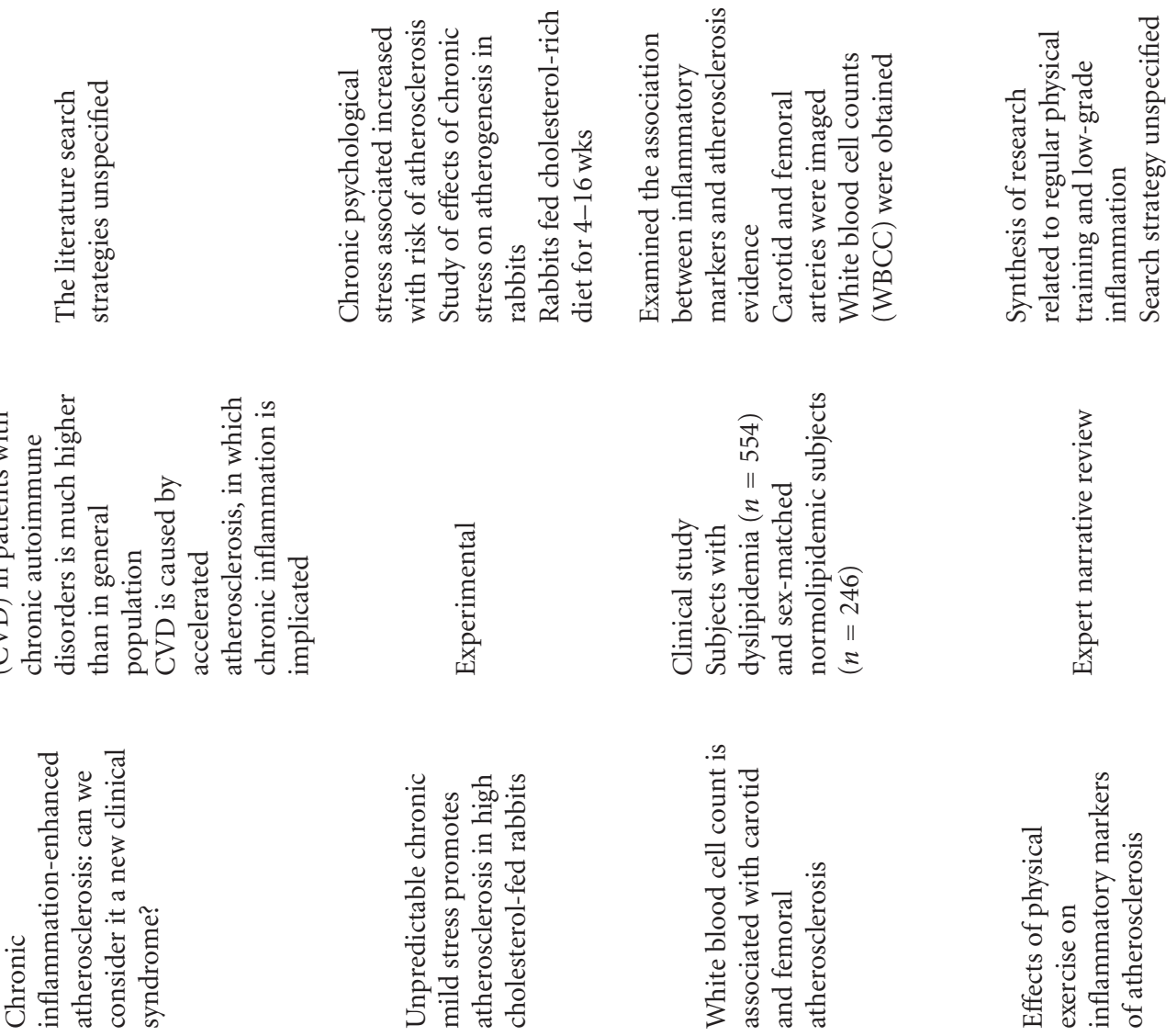

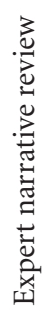
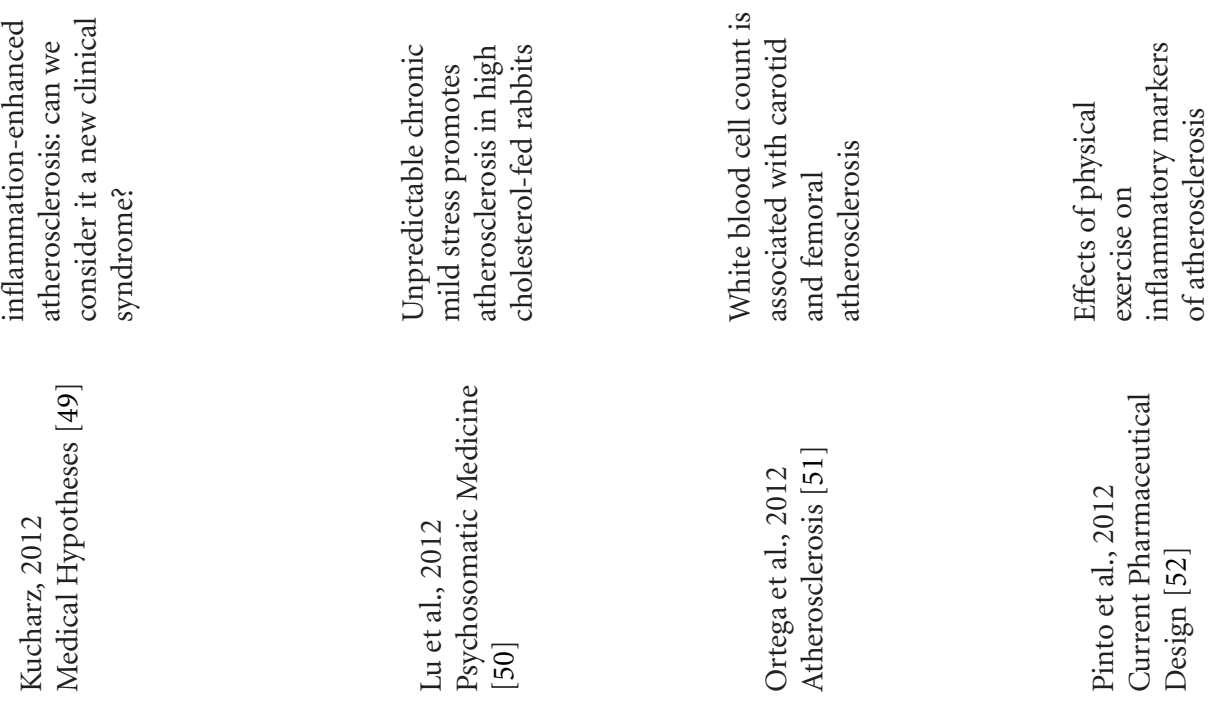


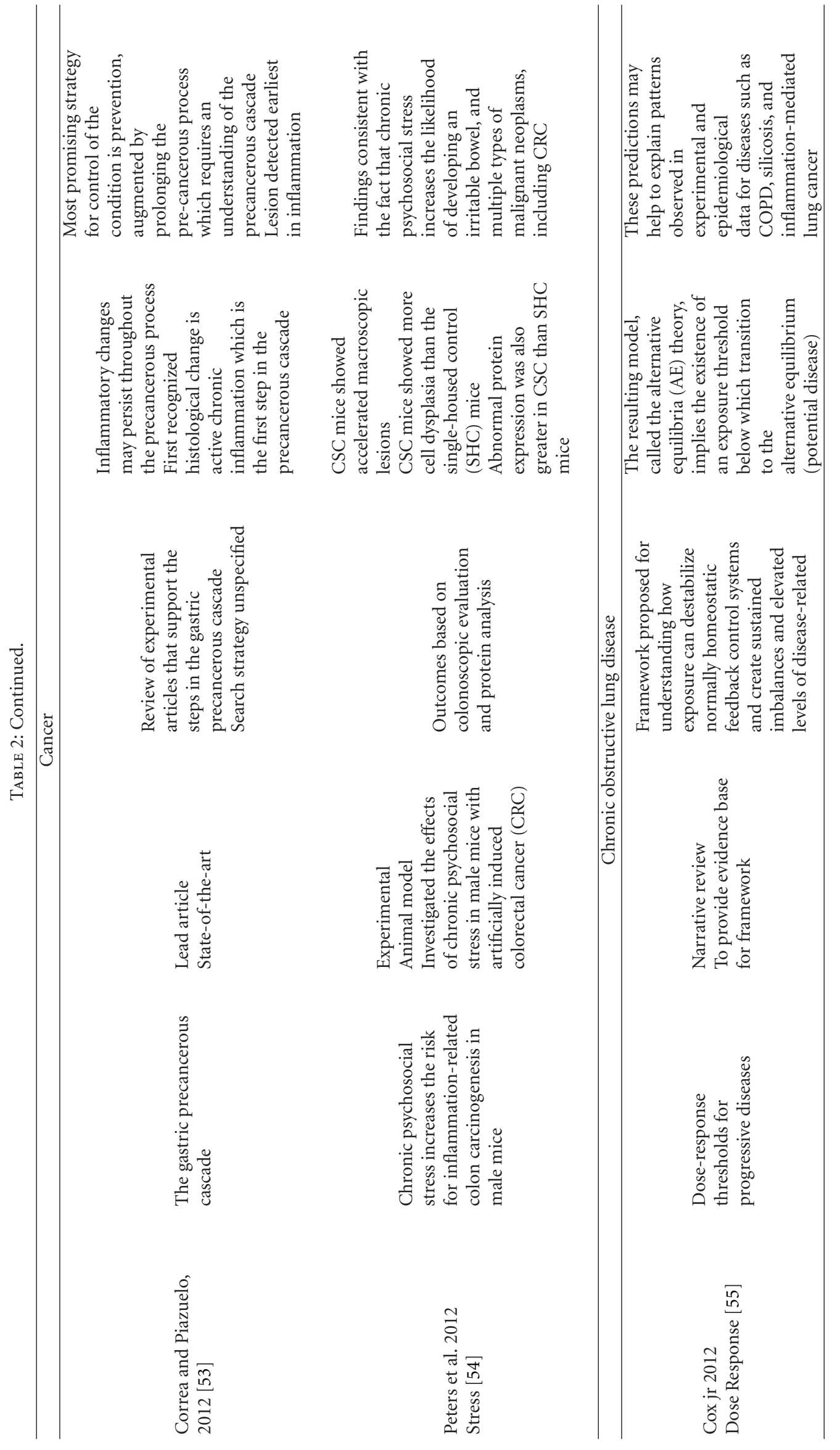



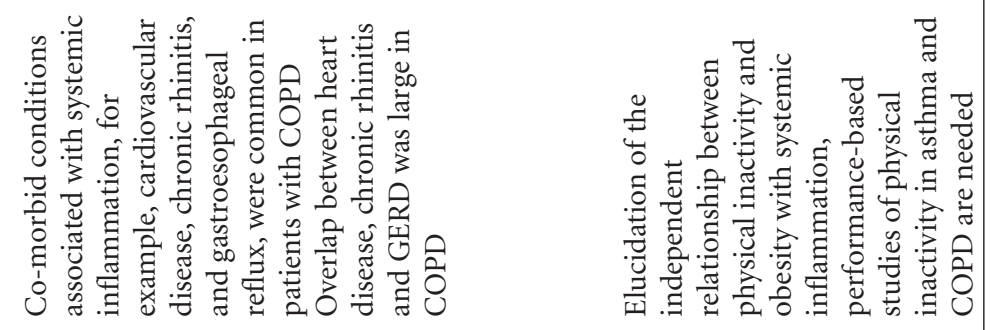

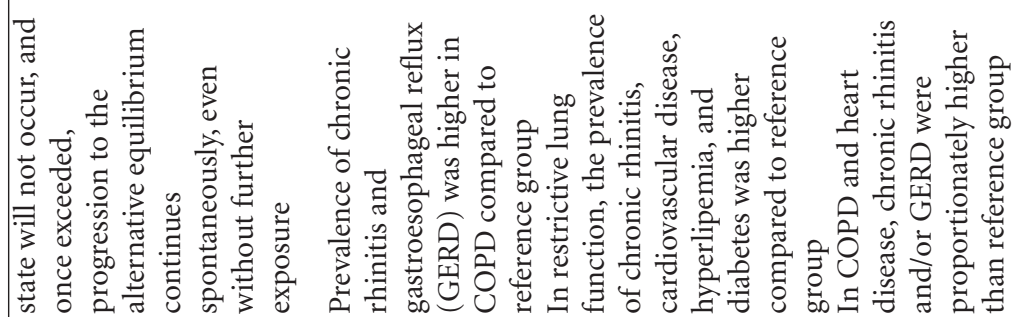
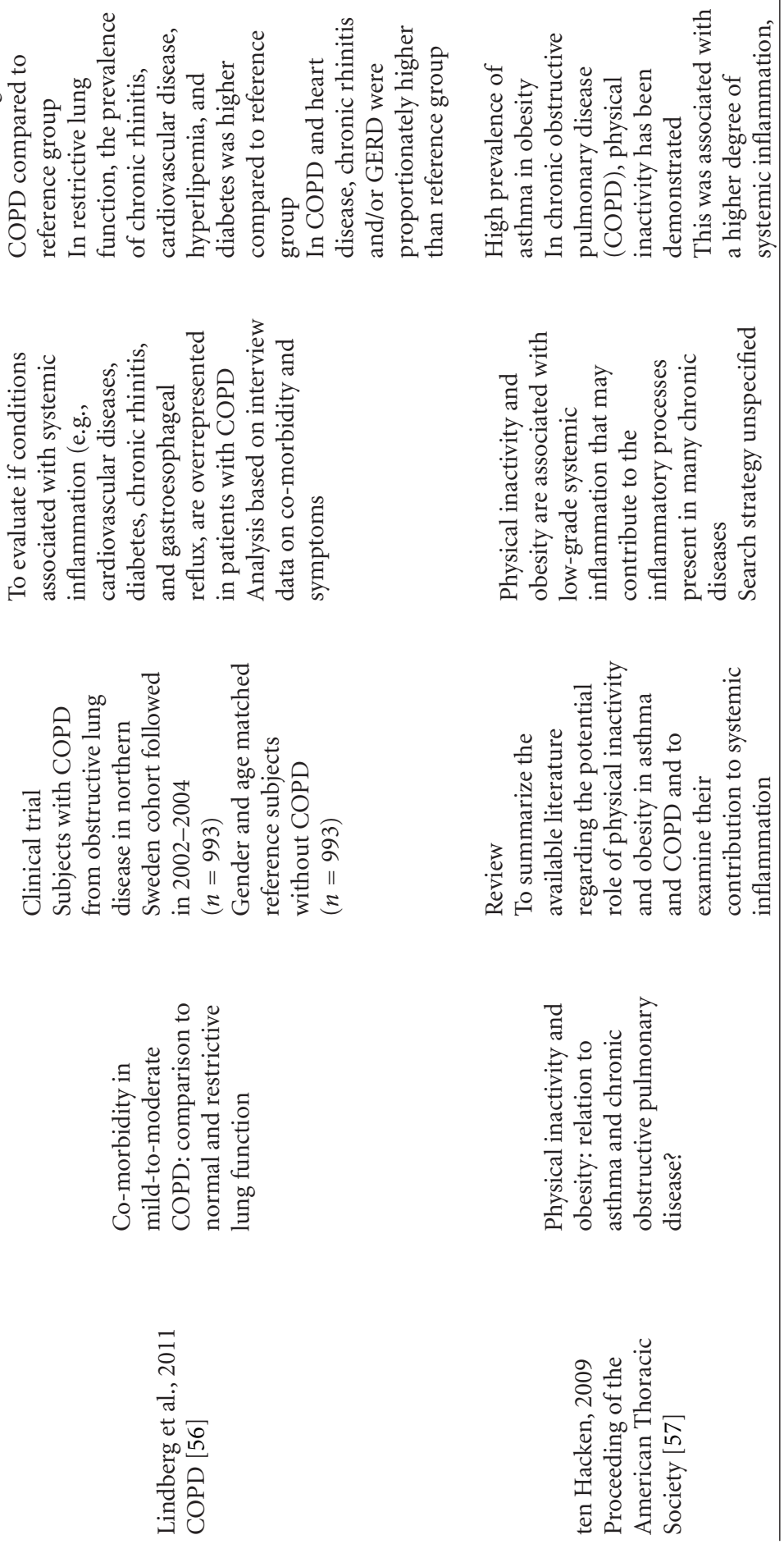


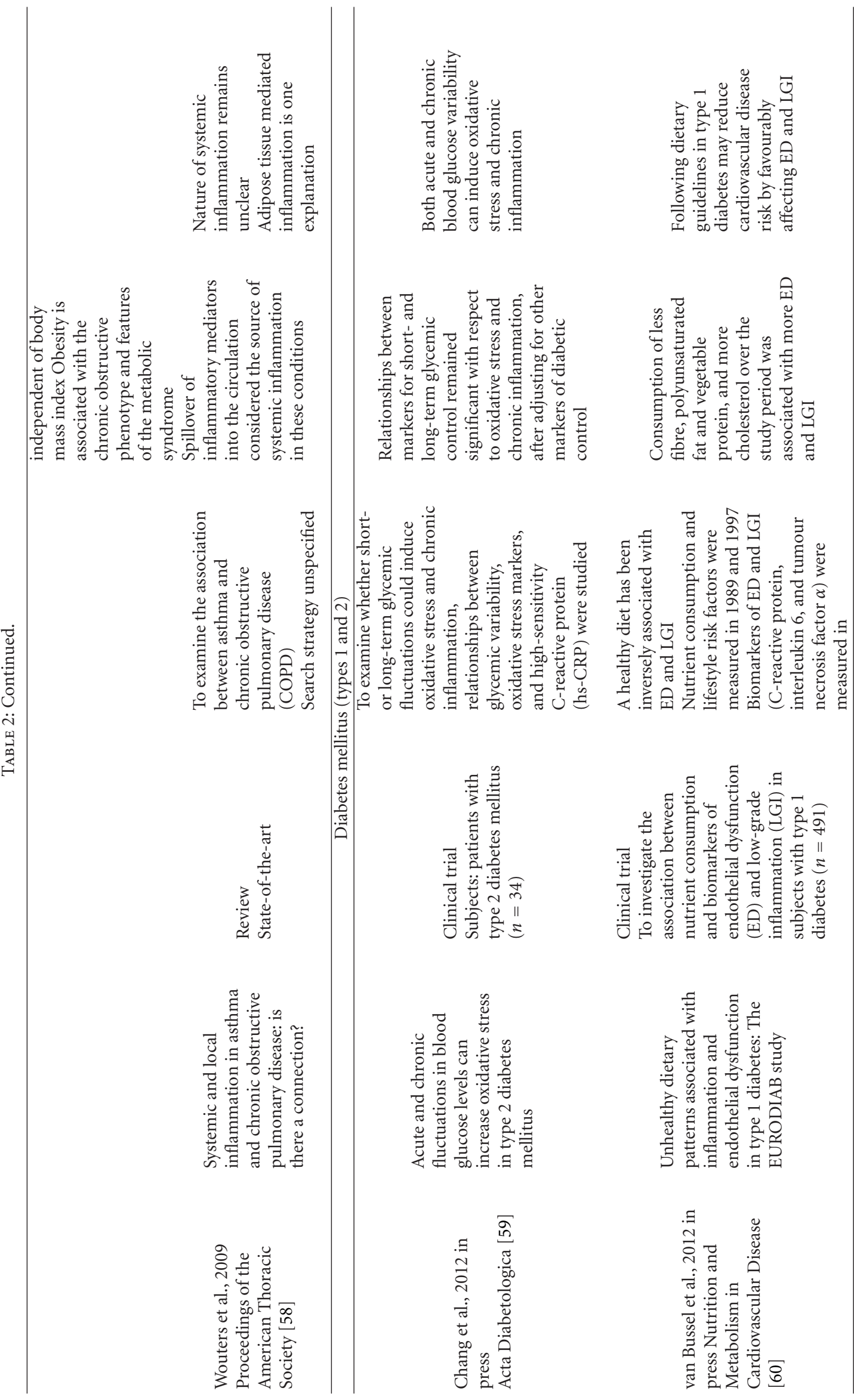




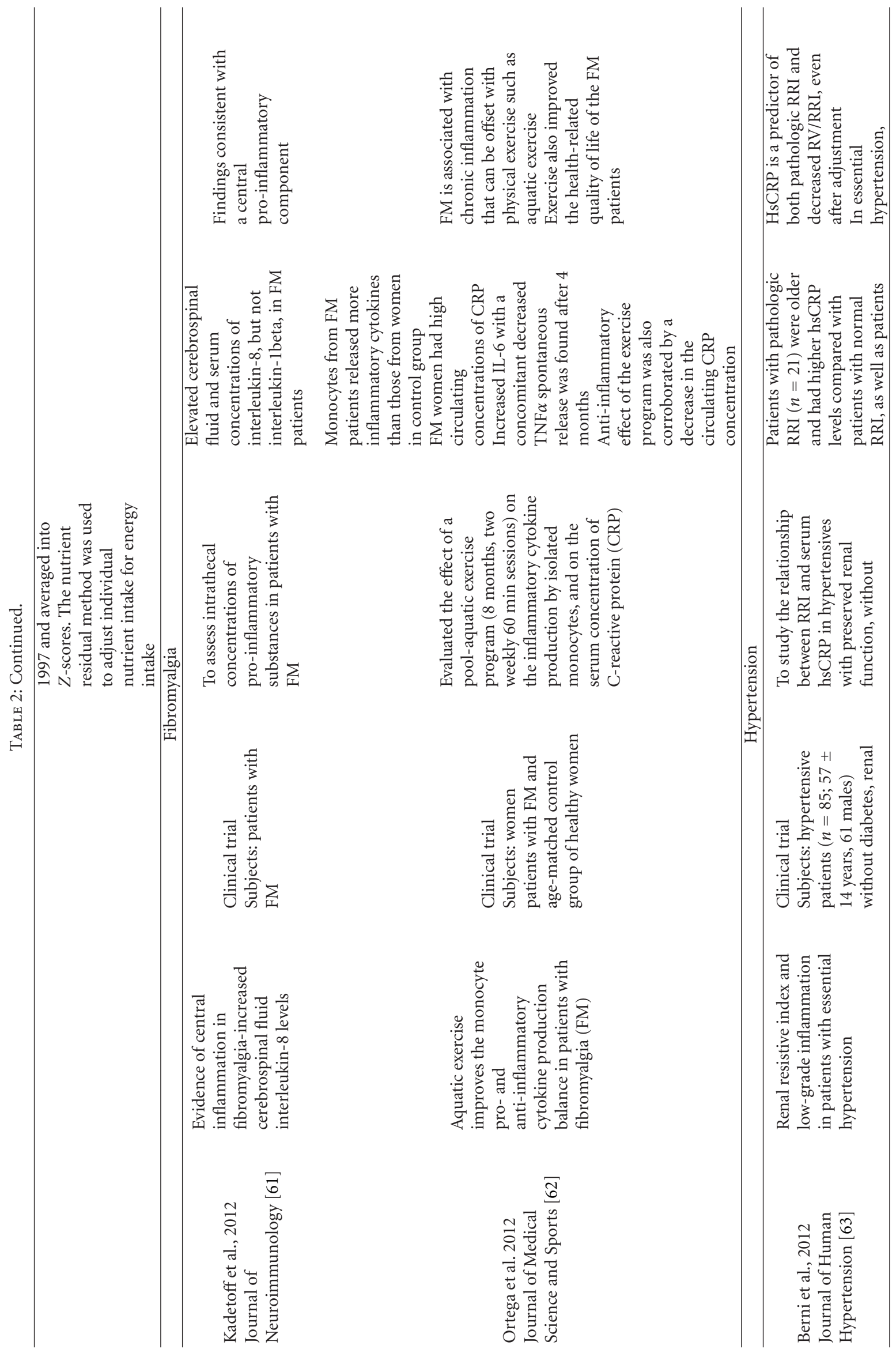




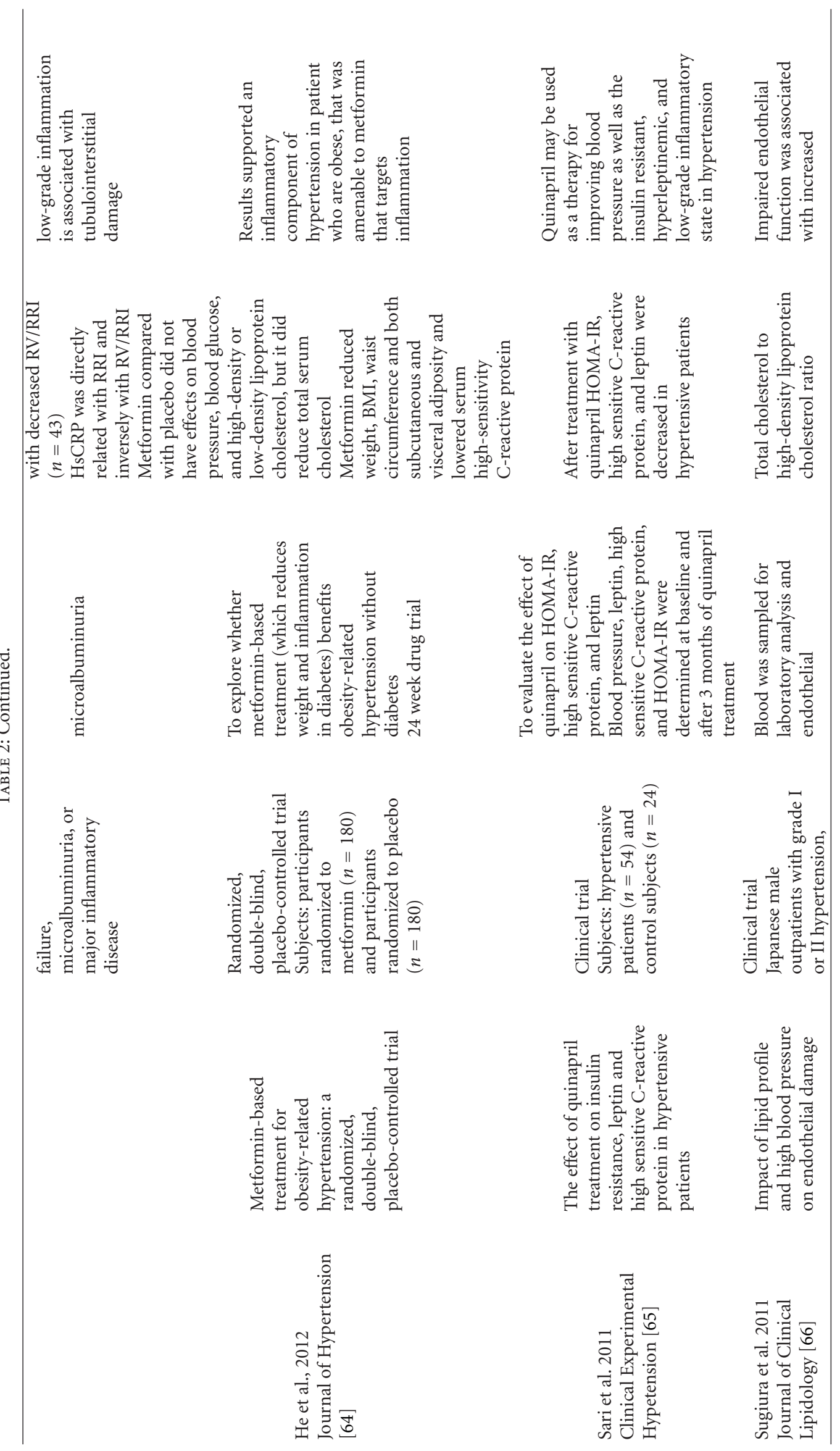




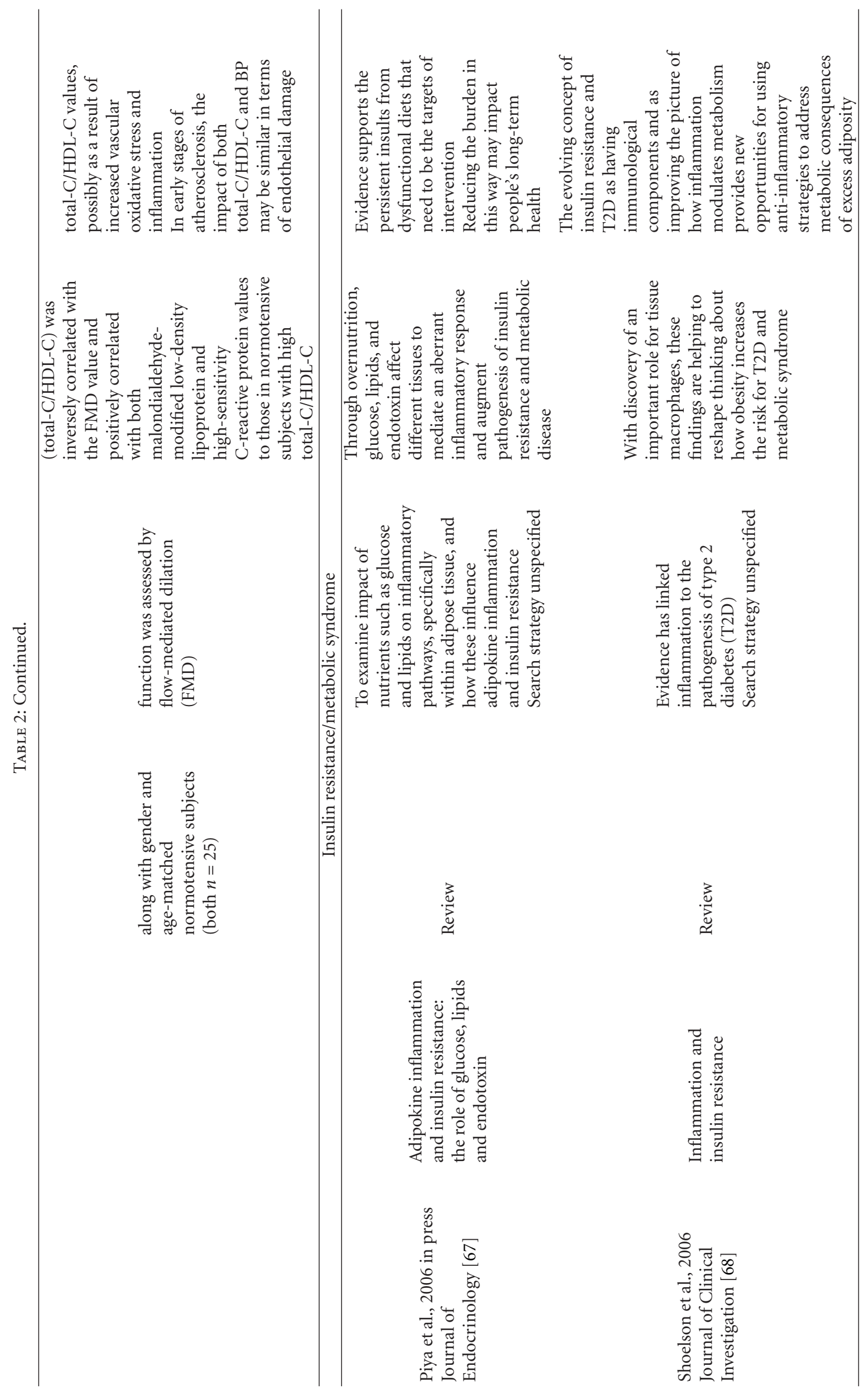




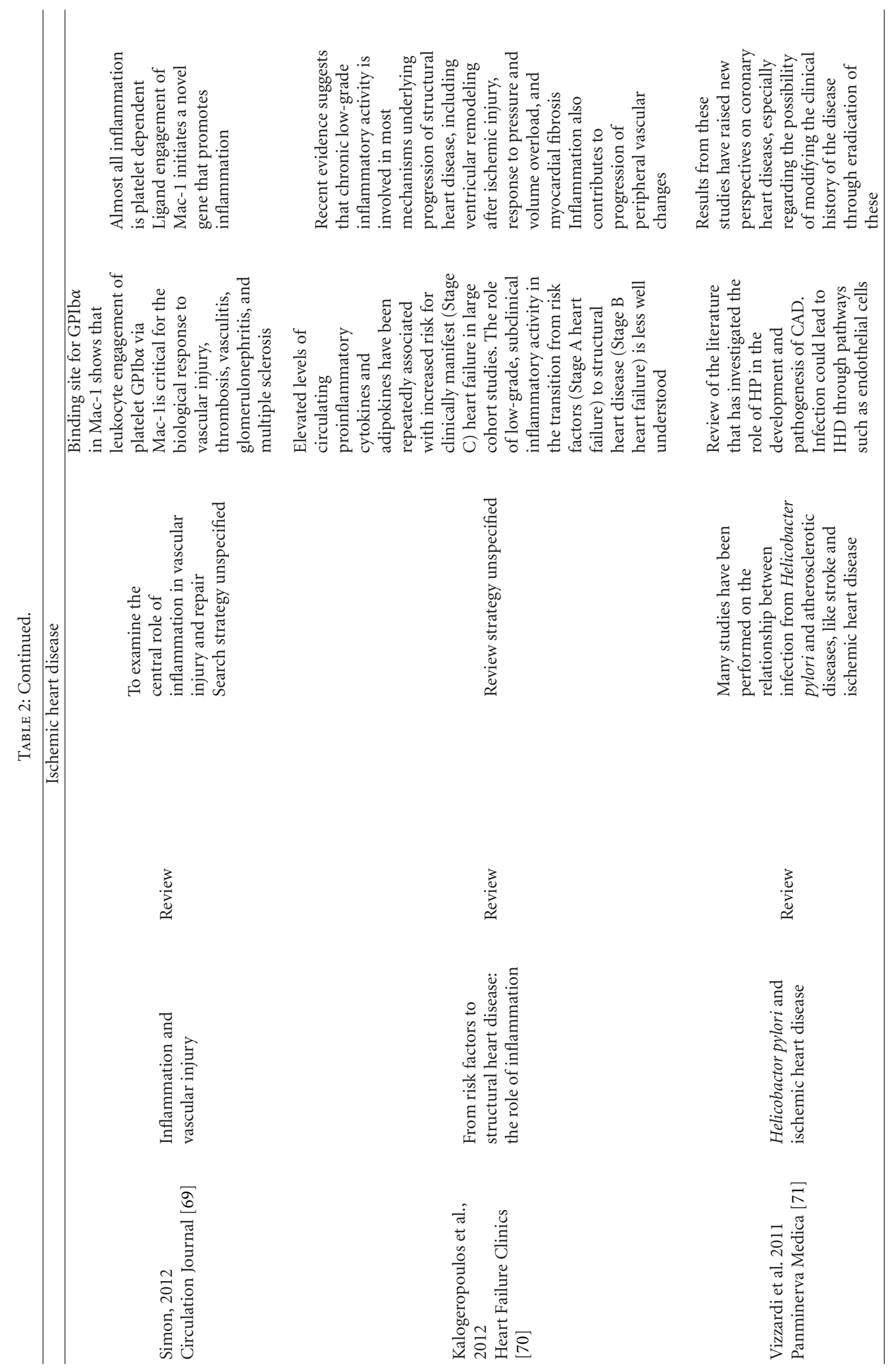




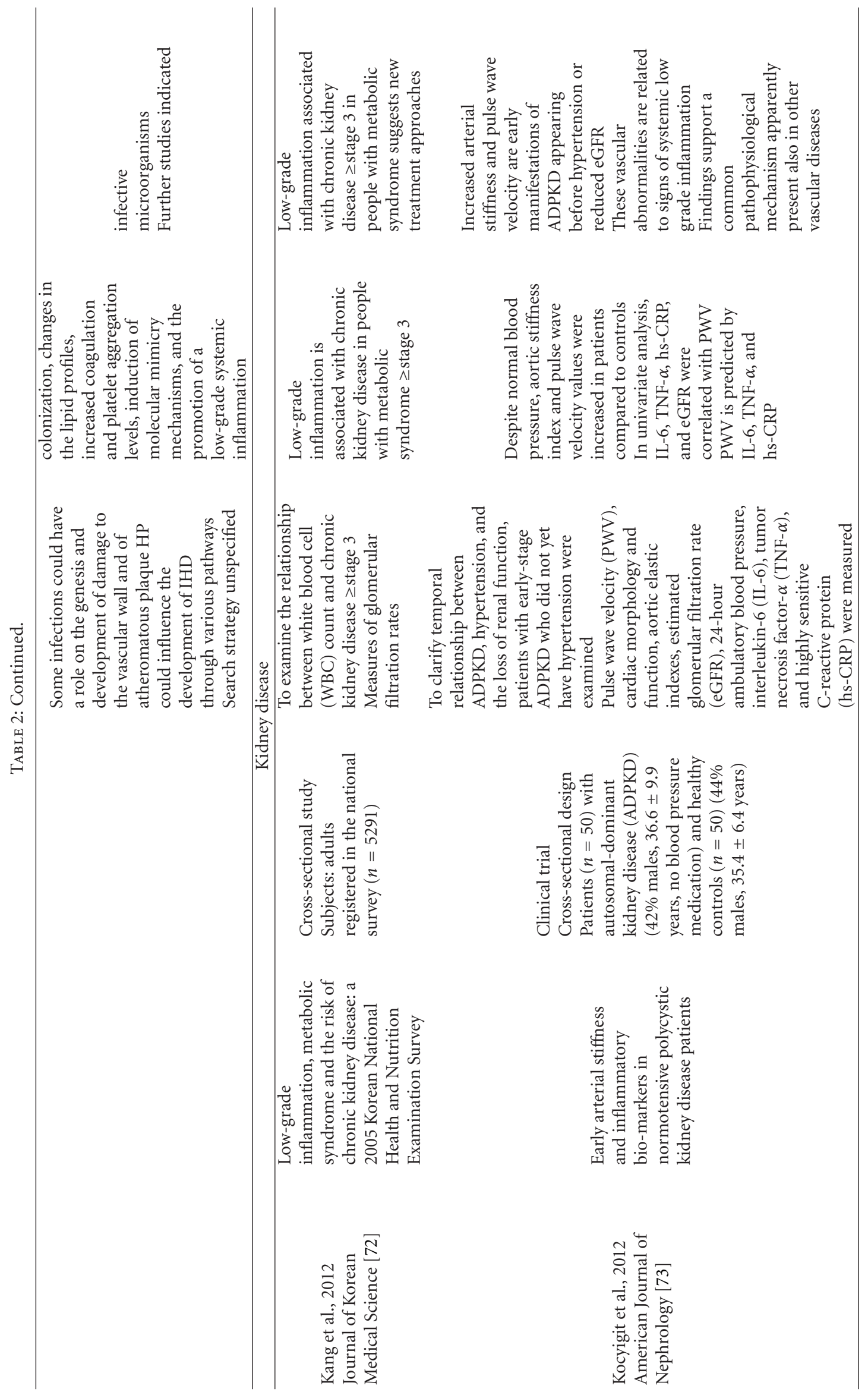




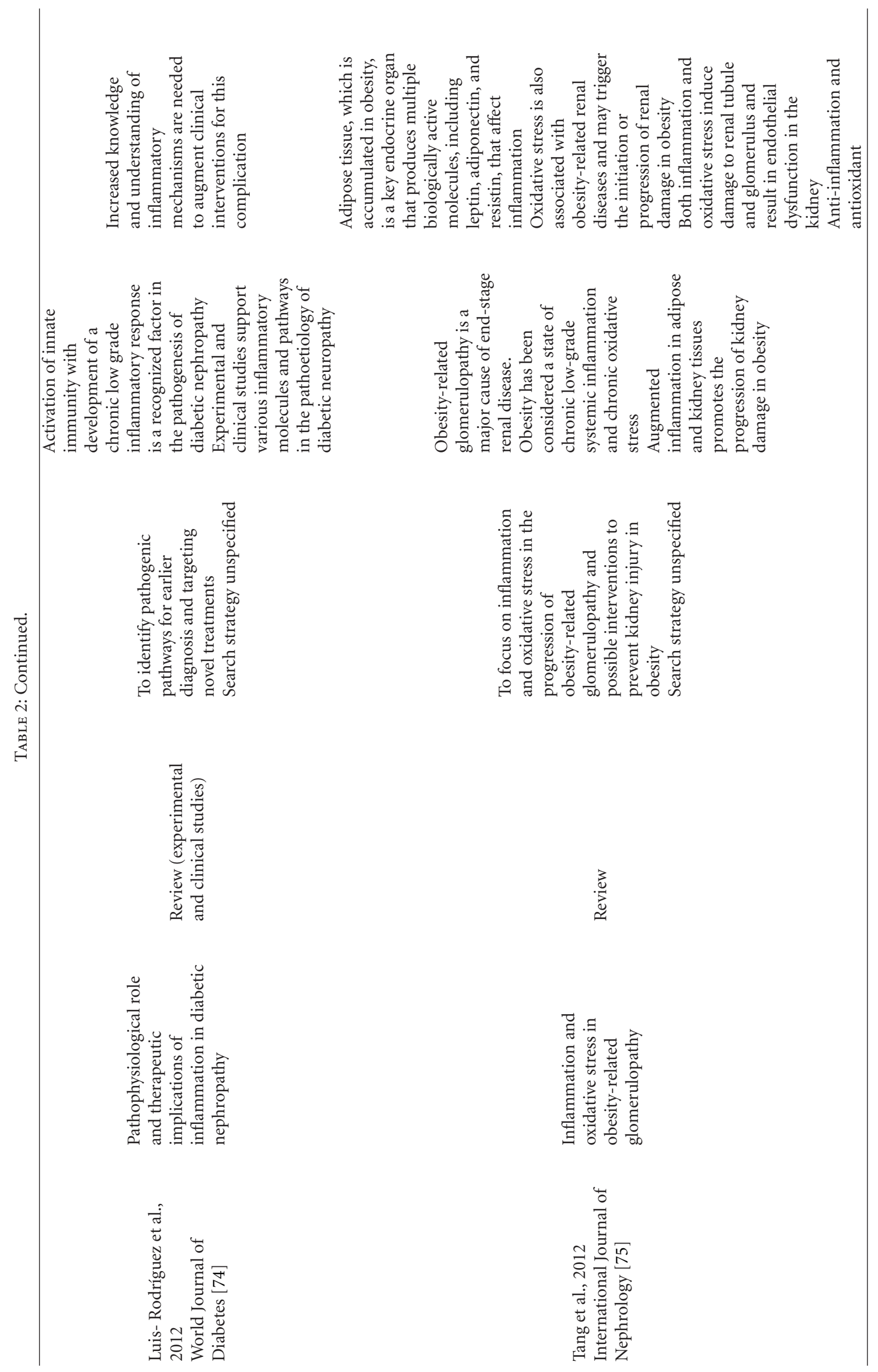




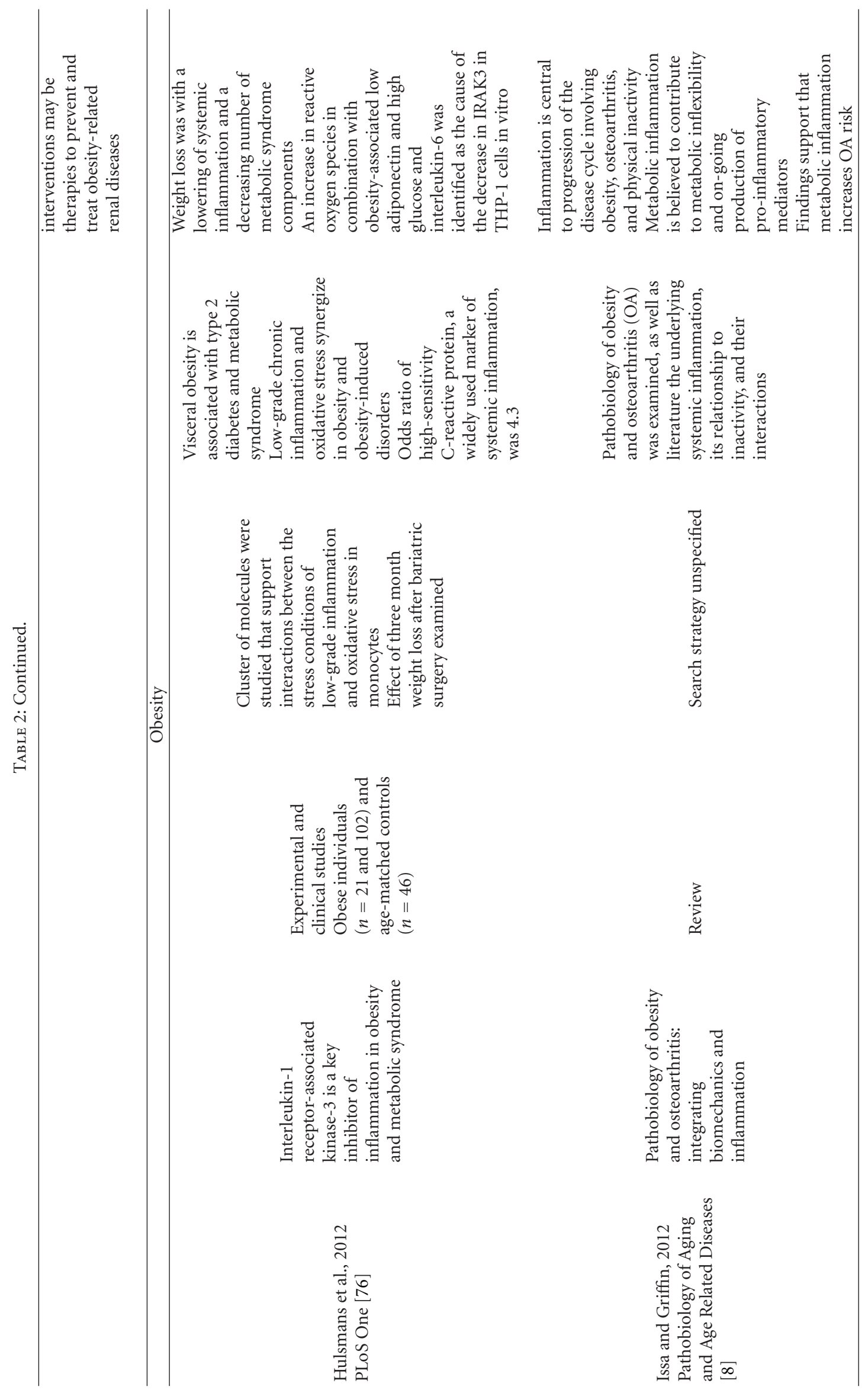




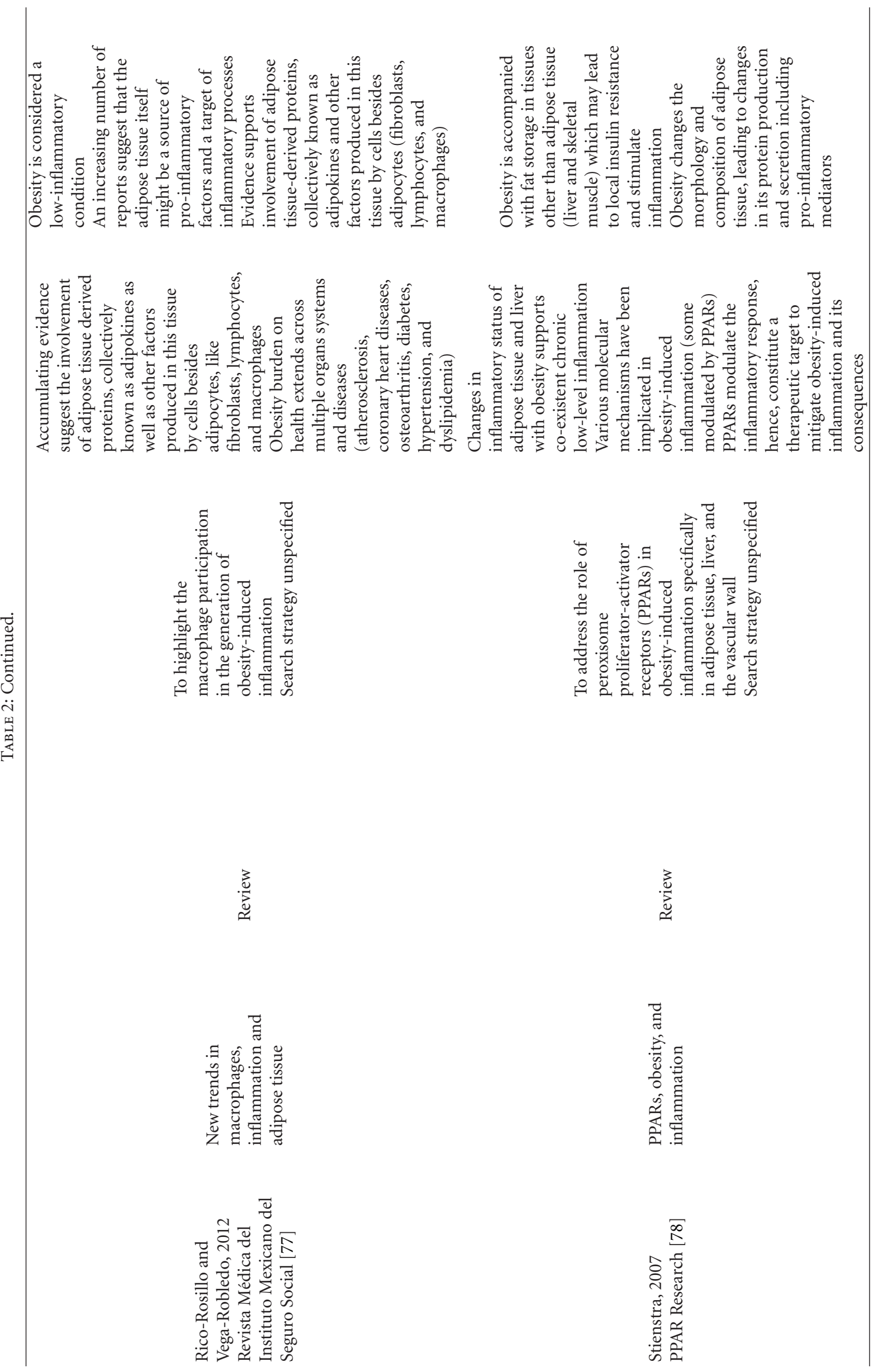




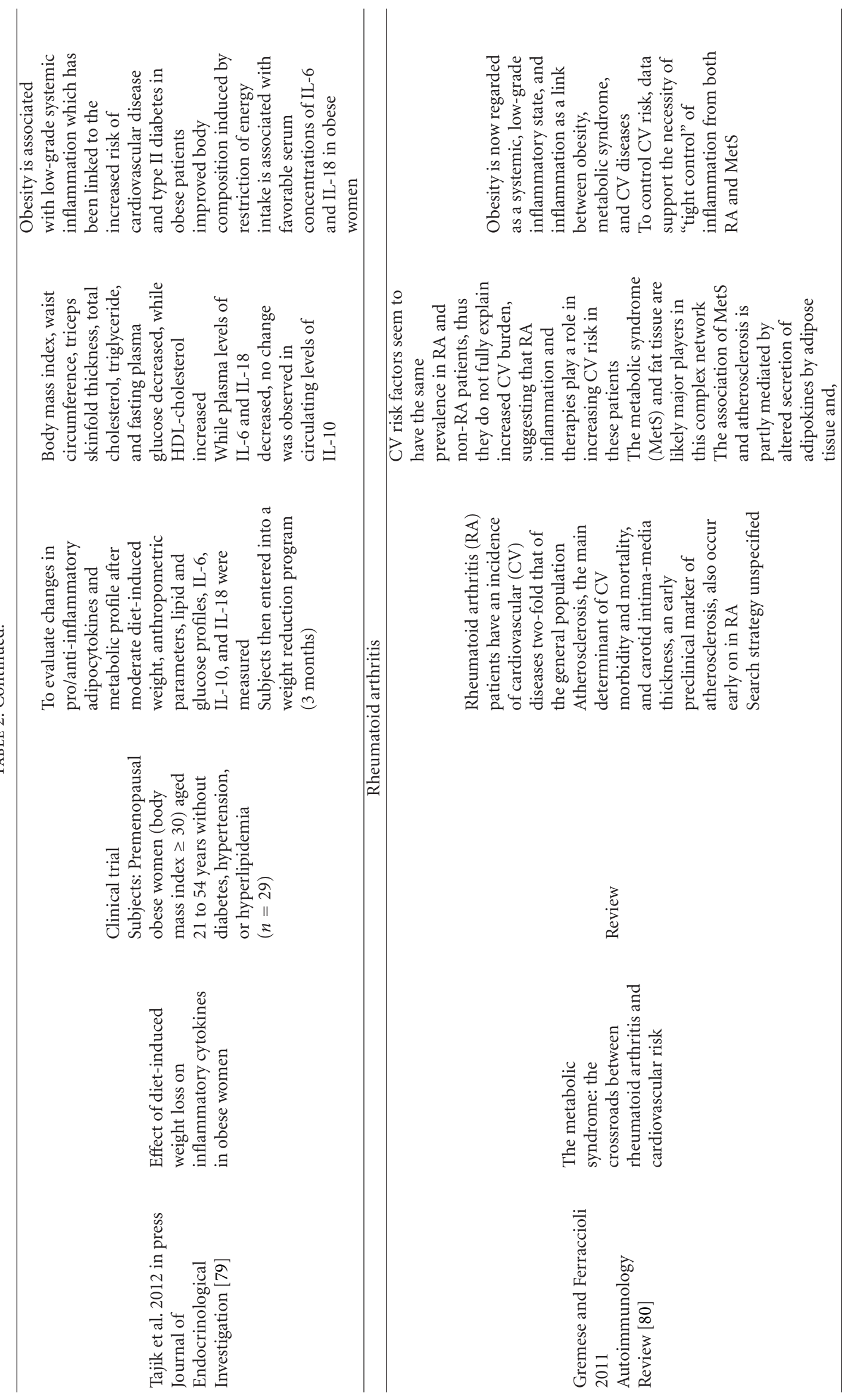




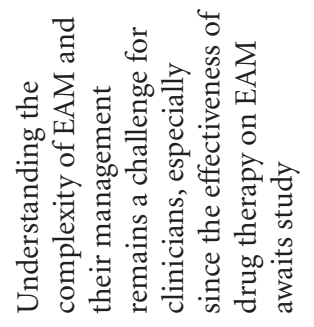

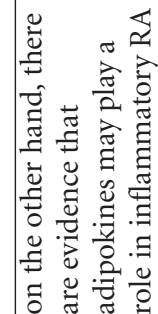
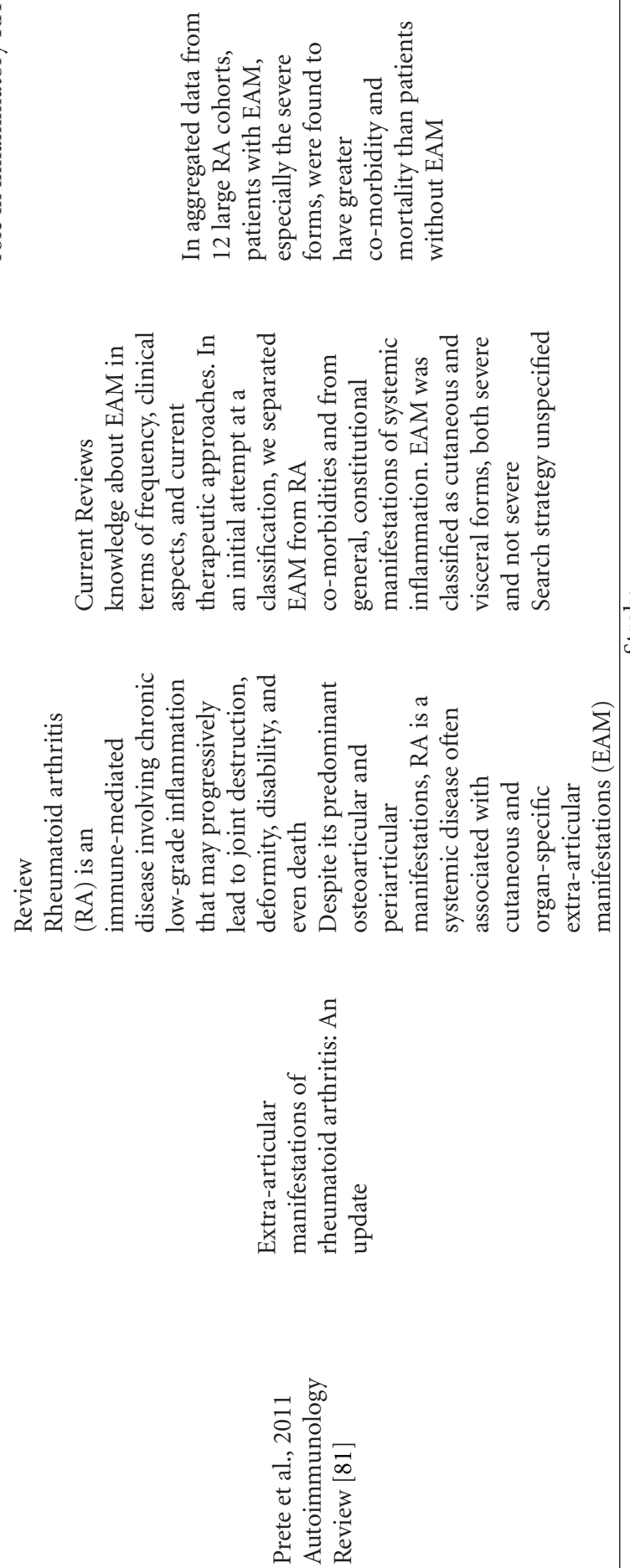

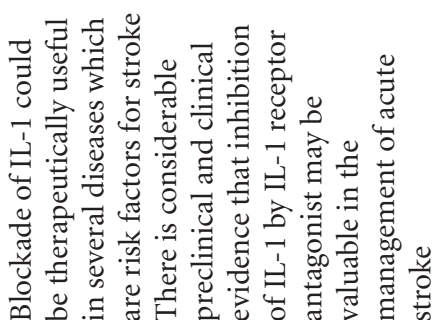

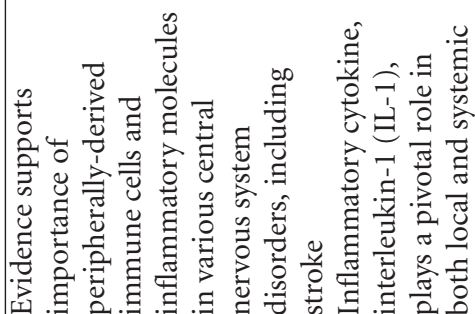

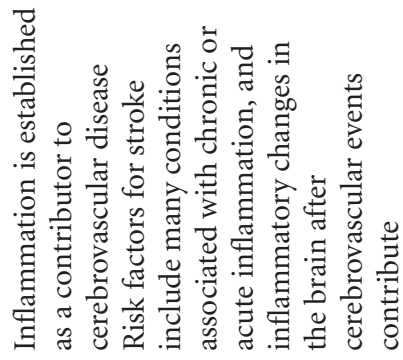

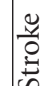

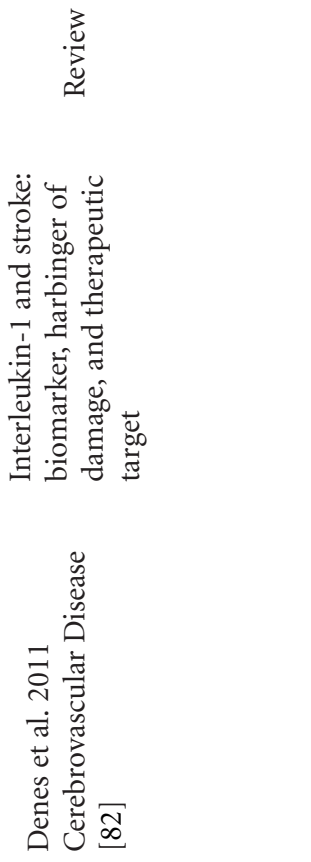




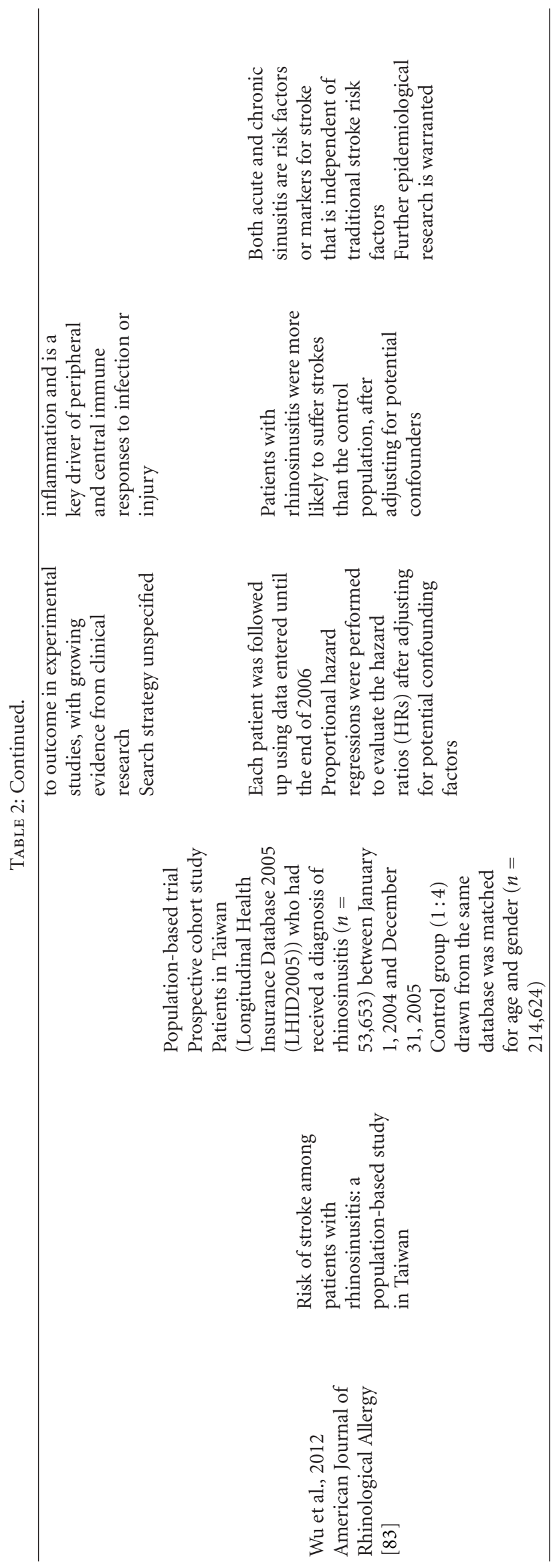


TABle 3: Pro- and anti-inflammatory foods (Source: [85-87]).

Proinflammatory foods

Alcohol

Regular high consumption irritates esophagus, larynx, and liver which can lead to chronic inflammation which promotes tumor growth at sites of chronic irritation Cooking oils

A diet of high imbalance of omega- 6 to omega- 3 ratio promotes inflammation (e.g., heart disease and cancer) Dairy products

Meat (commercially produced meats where animals are fed grains such as soy beans and corns (a diet high in inflammatory omega- 6 fatty acids and low in anti-inflammatory omega-3 fatty acids; also, these animals have limited exercise and raised to gain excess fat, ending up with high saturated fats. To make the animals grow faster and prevent them from getting sick, they are injected with hormones and fed antibiotics.)

Red meats (beef, lambs and pork) and processed meats (has, sausages, and salami)

Red meat contains a molecule humans do not naturally produce (Neu5Gc) that leads to the production of antibodies in defense of it, an immune response that may trigger chronic inflammation, and low grade inflammation (linked to heart disease and cancer)

Refined grains devoid of fiber and vitamin B compared with unrefined grains (have bran, germs and aleurone layer), refined grains like refined sugar with high glycemic index When consistently consumed hasten onset heart disease and cancer

Also often laden with fat and sugar and artificial flavors and partially hydrogenated oil

Artificial food additives

Aspartame and monosodium glutamate reportedly trigger inflammatory responses (particularly in those with inflammatory conditions, for example, rheumatoid arthritis Sugars

Trans fats (found in deep fried foods, commercially baked goods, and those prepared with partially dehydrongenated oil, margarine, and vegetable shortening
Anti-inflammatory foods

The "anti-inflammatory" nutritional plan includes the following.

Avoidance of sweets and sugar

Avoidance of high refined foods such as processed

foods (white bread and rice, and pasta)

Minimal fats (virgin olive oil okay as it has excellent anti-inflammatory properties)

High fiber foods including dark breads such as rye and pumpernickel

No alcohol

Recommended anti-inflammatory foods:

Oatmeal (not instant)

Asparagus, avocado, beets, Brussel sprouts, broccoli, cauliflower, kale, parsnip, spinach

Romaine lettuce

Berries

Strawberries, blueberries, raspberries, blackberries Green apples, oranges, pears, lemons, cantaloupe

Melon

Olives

Unsalted raw nuts

Sunflower seeds

Extra virgin olive oil

Water

Green tea

Beans, chickpeas, black beans

Lentils

Low-fat turkey/chicken

Eggs

Salmon

Low-sodium tuna packed in water

Dairy

Low-fat milk products are acceptable particularly plain yogurt, cottage, and solid cheeses, if any, like Swiss or cheddar, feta physical activity. With respect to nutrition, basic assessment can be done and education undertaken regarding patients' knowledge with the inflammatory characteristics of their diets and incorporating anti-inflammatory foods (see Table 3).

In addition, in the interest of best practice, as primary nonpharmacologic practitioners, contemporary physical therapists are integrating into practice health education including initiating and supporting smoking cessation, improved sleep hygiene, and stress management [94]. Given that smoking, poor sleep, and stress are all associated with low-grade inflammation and hyperimmune response, team members such as nutritionists and health counselors could be used to greater advantage on the health care team to promote effective health education related to health behavior change. In acute conditions, such education needs to be introduced potentially with pharmacologic intervention to reduce inflammation and pain expediently. However, as the acute episode subsides and the condition stabilizes, medication needs to be reduced as much as possible, and perhaps completely, as health living practices take maximal effect.

The benefits of healthy living have no better been exemplified than in an elegant but simple study reported by Ford and colleagues [95]. In their study of over 23,000 people between 35 and 65 years old, they reported that over an eightyear period, people who did not smoke; had a body mass index of less than $30 \mathrm{~kg} \cdot \mathrm{m}^{2}$; were physically active for at least 3.5 hours weekly; and ate healthily reduced their risk of type 2 diabetes mellitus by $93 \%$, myocardial infarction by $81 \%$, stroke by $50 \%$, and cancer by $36 \%$. Even if not all four health behaviors were present, risk of developing a chronic lifestylerelated condition decreased commensurate with an increase in the number of positive lifestyle factors. Furthermore, health-related quality of life increased with the number of healthy lifestyle behaviors that participants reported. In the 
process of conducting the present review of the literature, we identified no medication that was associated with such outcomes and such low risk of side effects, if any.

In the interest of best practice, healthy living recommendations need to be prescribed as uniquely for their direct effects on the pathoetiology of osteoarthritis, and prescribed as aggressively as first-line medications. Although general health recommendations are important for health promotion and disease prevention generally, the tenets of healthy living need to be systematically targeted to the patient's signs and symptoms and prescribed accordingly including long-term followup and support. Not doing so deprives the patient of evidence-informed best practice osteoarthritis management and care.

Consistent with healthy living as a first-line approach, patients' health behaviors need to be assessed in a measurable, reproducible, and standardized manner. In addition to questionnaires and self-reports, despite their limitations, inflammatory biomarkers such as C-reactive protein may be useful to objectively measure the effects of lifestyle behavior change rather than simply as an index of cardiovascular and diabetes risk [96-99].

To address the reports of health care practitioners about lack of knowledge and confidence to effect health behavior change, they have a range of evidence-based interventions at their disposal that are not time or resource intense [100102]. In addition, the 5's approach of behavior change, for example, has some evidence base and has been endorsed by the World Health Organization [103]. Its simplicity makes it attractive to health professionals, that is, assess: evaluate behavior change status (and progress), advise: personally relevant behavioral recommendations, agree: set specific collaborative, feasible goals, assist: anticipate barriers, problemsolve solutions, and complete action plan, and arrange: schedule followup, contacts, and resources.

In the interest of best practice, lifestyle behaviors need to be systematically assessed in every patient and monitored across the health professions the patient is seeing. Healthy living recommendations need to be prescribed as uniquely for their direct effects on the pathoetiology of osteoarthritis as medications are, and as aggressively if firstline management is to truly reflect evidence-based practice. Although general recommendations are important for health promotion and disease prevention generally, healthy living recommendations must be systematically targeted to the patient's signs and symptoms. In addition to integrating dietary and activity recommendations, smoking cessation, sleep hygiene, and stress reduction should be included in the interest of comprehensive effective care. Not doing so deprives the patient of best practice osteoarthritis management in relation to potential comorbidities that commonly present in this cohort.

\section{Implications: Clinical and Research}

The evidence supporting lifestyle behaviour change to address low-grade inflammation in people with osteoarthritis often with coexistent lifestyle-related risk factors and low-grade inflammatory conditions (specifically, antiinflammatory nutritional regimens, and moderate physical activity) is unequivocal. The evidence is sufficiently compelling for related healthy living assessment and recommendations be a component of first-line best practice in the management of the signs and symptoms of people with osteoarthritis. Assessments need to include lifestyle profiles related to body mass index, waist girth, and waist-to-hip ratio; physical activity and exercise, as well as smoking, sleep patterns, and stress (as these three latter factors have also been reported to be proinflammatory). When quantified in standardized ways, these profiles can serve as clinical outcomes to assess health behavior change interventions. The health behaviour change literature has exploded over the past two decades, yet health professions report lack of confidence in effecting health behavior change in their patients, and lack of resources including time [100]. Although much needs to be done, evidence-based interventions can be readily integrated into the framework of clinical practice and patient visits [101, 104], for example, brief advice, referral to others professionals, and followup). Physical therapists are particularly well positioned for initiating and supporting health behavior change in that patient visits tend to be prolonged and protracted over time, elements that are critical to effective long-term sustained health behavior change.

Studies are needed to examine the differentiating characteristics of those people with osteoarthritis who respond primarily to optimal nutrition and moderate physical activity, and those who do not. In addition, the elements of an anti-inflammatory nutrition regimen and moderate physical activity program need to be refined in terms of their prescriptive parameters, specifically, which elements should be a primary focus for which patients. Another line of studies is needed to examine the effect of such healthy lifestyle choices that increase inflammation threshold, on the need for medication and, if medication is indicated, how might its potency and dosage be reduced. The interactions among healthy lifestyle behaviors and pharmacokinetics need to be elucidated. Given that chronic systemic low-grade inflammation has been reported to be a common denominator of lifestyle-related conditions, studies are needed to establish the degree to which their risk factors and manifestations are reduced in people with chronic osteoarthritis whose firstline management includes prescribing optimal nutrition and physical activity for their anti-inflammatory effects. Furthermore, the impact of low-grade inflammation can be more far reaching than physical complaints alone, in that even healthy older adults report poorer health commensurate with level of inflammatory markers [105]. Lastly, all indicators support that the approach to chronic progressive conditions such as osteoarthritis needs to be holistic and interprofessional [106]. Research is needed to capture the breadth of this evidence-informed practice approach.

\section{Conclusion}

Based on the extant literature, exploitation of anti-inflammatory lifestyle behavior change as "first-line" intervention in the management of chronic osteoarthritis could well 
constitute best practice. Chronic low-grade inflammation that has been reported in chronic osteoarthritis is comparable to other lifestyle-related conditions supporting a common mechanism of action. Addressing chronic low-grade inflammation by focussing on lifestyle factors that contribute directly to it holds the promise of increasing a patient's inflammatory threshold, reducing rate of disease progression, reducing weight, and maximizing health by minimizing a patient's risk or manifestations of other lifestyle-related conditions. Even in part, such outcomes could minimize demands on physicians for short-term symptom reduction, and management of the patient's comorbidity related to lifestyle-related conditions. "First-line" lifestyle interventions to address chronic low-grade inflammation provides an informed cost-effective basis for the 21 st century prevention, potential reversal, and management of chronic osteoarthritis. Exploitation of such "first-line" intervention, however, needs to be a goal shared and supported by all healthcare team members.

\section{References}

[1] L. Brosseau, G. A. Wells, P. Tugwell et al., "Ottawapanel evidence-based clinical practice guidelines for the management of osteoarthritis in adults who are obese or overweight," Physical Therapy, vol. 91, no. 6, pp. 843-860, 2011.

[2] M. C. Hochberg, R. D. Altman, K. T. April et al., "American College of Rheumatology 2012. Recommendations for the use of nonpharmacologic and pharmacologic therapies in osteoarthritis of the hand, hip, and knee," Arthritis Care Research, vol. 64, pp. 465-474, 2012.

[3] N. E. Lane and J. M. Thompson, "Management of osteoarthritis in the primary-care setting: an evidence- based approach to treatment," American Journal of Medicine A, vol. 103, no. 6, pp. 25S-30S, 1997.

[4] Osteoarthritis, "National clinical guideline for care and management in adults," The National Collaborative Centre for Chronic Conditions. Royal College of Physicians of London, http://bookshop.rcplondon.ac.uk/contents/ pub242-66a1af7e-27ae-4121-bd84-6b503c80a64e.pdf, 2008.

[5] W. Zhang, G. Nuki, R. W. Moskowitz et al., "OARSI recommendations for the management of hip and knee osteoarthritis. Part III: changes in evidence following systematic cumulative update of research published through January 2009," Osteoarthritis and Cartilage, vol. 18, no. 4, pp. 476-499, 2010.

[6] A. Barr and P. G. Conaghan, "Osteoarthritis: a holistic approach," Clinical Medicine, vol. 12, no. 2, pp. 153-155, 2012.

[7] N. Hairon, "New guidance on osteoarthritis focuses on patient education," Nursing times, vol. 104, no. 10, pp. 21-22, 2008.

[8] R. I. Issa and T. M. Griffin, "Pathobiology of obesity and osteoarthritis: integrating biomechanics and inflammation," Pathobiology of Aging and Age Related Diseases, vol. 2012, Article ID 17470, 2 pages, 2012.

[9] D. L. Cecil, K. Johnson, J. Rediske, M. Lotz, A. M. Schmidt, and R. Terkeltaub, "Inflammation-induced chondrocyte hypertrophy is driven by receptor for advanced glycation end products," Journal of Immunology, vol. 175, no. 12, pp. 82968302, 2005.

[10] J. Rojas-Rodríguez, L. E. Escobar-Linares, M. GarciaCarrasco, R. O. Escárcega, S. Fuentes-Alexandro, and A.
Zamora-Ustaran, "The relationship between the metabolic syndrome and energy-utilization deficit in the pathogenesis of obesity-induced osteoarthritis," Medical Hypotheses, vol. 69, no. 4, pp. 860-868, 2007.

[11] N. Schlesinger and R. G. Thiele, "The pathogenesis of bone erosions in gouty arthritis," Annals of the Rheumatic Diseases, vol. 69, no. 11, pp. 1907-1912, 2010.

[12] M. D. Smith, S. Triantafillou, A. Parker, P. P. Youssef, and M. Coleman, "Synovial membrane inflammation and cytokine production in patients with early osteoarthritis," Journal of Rheumatology, vol. 24, no. 2, pp. 365-371, 1997.

[13] E. Dean, S. Al-Obaidi, A. D. de Andrade et al., "The first physical therapy summit on global health: implications and recommendations for the 21st century," Physiotherapy Theory and Practice, vol. 27, no. 8, pp. 531-547, 2011.

[14] World Health Organization, Chronic Diseases, http://www .who.int/topics/chronic_diseases/en/, 2005.

[15] P. Carrera-Bastos, M. Fontes-Villalba, J. H. O. Keefe, S. Lindeberg, and L. Cordain, "The western diet and lifestyle and diseases of civilization," Research Reports in Clinical Cardiology, vol. 2, pp. 15-35, 2012.

[16] B. Caballero, "Obesity as a consequence of undernutrition," Journal of Pediatrics, vol. 149, no. 3, pp. S97-S99, 2006.

[17] G. Engström, M. Gerhardsson de Verdier, J. Rollof, P. M. Nilsson, and L. S. Lohmander, "C-reactive protein, metabolic syndrome and incidence of severe hip and knee osteoarthritis. A population-based cohort study," Osteoarthritis and Cartilage, vol. 17, no. 2, pp. 168-173, 2009.

[18] L. Landaeta-Díaz, J. M. Fernández, M. Da Silva-Grigoletto et al., "Mediterranean diet, moderate-to-high intensitytraining and health-related quality of life in adults with metabolic syndrome," European Journal of Preventive Cardiology. In press.

[19] T. C. Campbell, "A study on diet, nutrition and disease in the People's Republic of China. Part I," Boletin de la Asociacion Medica de Puerto Rico, vol. 82, no. 3, pp. 132-134, 1990.

[20] T. C. Campbell and C. Junshi, "Diet and chronic degenerative diseases: perspectives from China," American Journal of Clinical Nutrition, vol. 59, supplement 1, pp. 1153S-1153S, 1994.

[21] T. C. Campbell and T. M. Campbell, The China Study, Benbella Books, Dallas, Tex, USA, 2006.

[22] T. C. Campbell, B. Parpia, and J. Chen, "Diet, lifestyle, and the etiology of coronary artery disease: the Cornell China Study," American Journal of Cardiology B, vol. 82, no. 10, pp. 18T-21T, 1998.

[23] S. Gregersen, D. Samocha-Bonet, L. K. Heilbronn, and L. V. Campbell, "Inflammatory and oxidative stress responses to high-carbohydrate and high-fat meals in healthy humans," Journal of Nutrition and Metabolism, vol. 2012, Article ID 238056, 8 pages, 2012.

[24] B. J. Nicklas, W. Ambrosius, S. P. Messier et al., "Dietinduced weight loss, exercise, and chronic inflammation in older, obese adults: a randomized controlled clinical trial," American Journal of Clinical Nutrition, vol. 79, no. 4, pp. 544551, 2004.

[25] M. A. Allison, N. E. Jensky, S. J. Marshall, A. G. Bertoni, and M. Cushman, "Sedentary behavior and adiposity-associated inflammation: the multi-ethnic study of atherosclerosis," American Journal of Preventive Medicine, vol. 42, no. 1, pp. 8-13, 2012.

[26] M. Gleeson, N. C. Bishop, D. J. Stensel, M. R. Lindley, S. S. Mastana, and M. A. Nimmo, "The anti-inflammatory effects of exercise: mechanisms and implications for the prevention 
and treatment of disease," Nature Reviews Immunology, vol. 11, no. 9, pp. 607-615, 2011.

[27] A. M. W. Petersen and B. K. Pedersen, "The anti-inflammatory effect of exercise," Journal of Applied Physiology, vol. 98, no. 4, pp. 1154-1162, 2005.

[28] Exercise helps ease arthritis pain and stiffness, http://www .mayoclinic.com/health/arthritis/AR00009, 2012.

[29] N. P. Walsh, M. Gleeson, R. J. Shephard et al., "Position statement. Part one: immune function and exercise," Exercise Immunology Review, vol. 17, pp. 6-63, 2011.

[30] M. Gurevich, P. M. Kohn, and C. Davis, "Exercise-induced analgesia and the role of reactivity in pain sensitivity," Journal of Sports Sciences, vol. 12, no. 6, pp. 549-559, 1994.

[31] R. B. Singh, G. Dubnov, M. A. Niaz et al., "Effect of an IndoMediterranean diet on progression of coronary artery disease in high risk patients (Indo-Mediterranean Diet Heart Study): a randomised single-blind trial," The Lancet, vol. 360, no. 9344, pp. 1455-1461, 2002.

[32] J. Lee, V. Taneja, and R. Vassallo, "Cigarette smoking and inflammation cellular and molecular mechanisms," Journal of Dental Research, vol. 91, no. 2, pp. 142-149, 2012.

[33] R. B. Gonçalves, R. D. Coletta, K. G. Silvério et al., "Impact of smoking on inflammation: overview of molecular mechanisms," Inflammation Research, vol. 60, no. 5, pp. 409424, 2011.

[34] A. Bakhru and T. P. Erlinger, "Smoking cessation and cardiovascular disease risk factors: results from the third national health and nutrition examination survey," PLoS Medicine, vol. 2, no. 6, pp. 0528-0536, 2005.

[35] Z. Baka, E. Buzás, and G. Nagy, "Rheumatoid arthritis and smoking: putting the pieces together," Arthritis Research \& Therapy, vol. 11, no. 4, p. 238, 2009.

[36] S. Amin, J. Niu, A. Guermazi et al., "Cigarette smoking and the risk for cartilage loss and knee pain in men with knee osteoarthritis," Annals of the Rheumatic Diseases, vol. 66, no. 1, pp. 18-22, 2007.

[37] P. H. Black, "Stress and the inflammatory response: a review of neurogenic inflammation," Brain, Behavior, and Immunity, vol. 16, no. 6, pp. 622-653, 2002.

[38] P. H. Black, "The inflammatory response is an integral part of the stress response: implications for atherosclerosis, insulin resistance, type II diabetes and metabolic syndrome X," Brain, Behavior, and Immunity, vol. 17, no. 5, pp. 350-364, 2003.

[39] S. Cohen, D. Janicki-Deverts, W. J. Doyle et al., "Chronic stress, glucocorticoid receptor resistance, inflammation, and disease risk," Proceedings of the National Academy of Science, vol. 109, no. 16, pp. 5995-5999, 2012.

[40] M. Maes, "Psychological stress and the inflammatory response system," Clinical Science, vol. 101, no. 2, pp. 193194, 2001.

[41] T. Pedersen, "Lack of sleep, stress leads to inflammation in older adults," Psychology Central, http://psychcentral.com/ news/2012/03/02/lack-of-sleep-stress-leads-to-inflammation-in-older-adults/35490.html, 2012.

[42] B. Giunta, F. Fernandez, W. V. Nikolic et al., "Inflammaging as a prodrome to Alzheimer's disease," Journal of Neuroinflammation, vol. 5, p. 51, 2008.

[43] R. Veerhuis, "Histological and direct evidence for the role of complement in the neuroinflammation of AD," Current Alzheimer Research, vol. 8, no. 1, pp. 34-58, 2011.

[44] G. Candore, C. Caruso, E. Jirillo, T. Magrone, and S. Vasto, "Low grade inflammation as a common pathogenetic denominator in age-related diseases: novel drug targets for anti-ageing strategies and successful ageing achievement," Current Pharmaceutical Design, vol. 16, no. 6, pp. 584-596, 2010.

[45] K. T. Chou, C. C. Huang, Y. M. Chen et al., "Asthma and risk of erectile dysfunction-A nationwide population-based study," Journal of Sexual Medicine, vol. 8, no. 6, pp. 17541760, 2011.

[46] A. Dixon, "The treatment of asthma in obesity," Expert Reviews in Respiratory Medicine, vol. 6, no. 3, pp. 331-340, 2012.

[47] C. T. Juel, Z. Ali, L. Nilas, and C. S. Ulrik, "Asthma and obesity: does weight loss improve asthma control? A systematic review," Journal of Asthma and Allergy, vol. 5, pp. 21-26, 2012.

[48] H. F. Gu, C. K. Tang, and Y. Z. Yang, "Psychological stress, immune response, and atherosclerosis," Atherosclerosis, vol. 223, no. 1, pp. 69-77, 2012.

[49] E. J. Kucharz, "Chronic inflammation-enhanced atherosclerosis: can we consider it as a new clinical syndrome?" Medical Hypotheses, vol. 78, no. 3, pp. 396-397, 2012.

[50] X. T. Lu, Y. F. Liu, L. Zhang et al., "Unpredictable chronic mild stress promotes atherosclerosis in high cholesterol-fed rabbits," Psychosomatic Medicine, vol. 74, no. 6, pp. 604-611, 2012.

[51] E. Ortega, R. Gilabert, I. Nuñez et al., "White blood cell count is associated with carotid and femoral atherosclerosis," Atherosclerosis, vol. 221, no. 1, pp. 275-281, 2012.

[52] A. Pinto, D. Di Raimondo, A. Tuttolomondo, C. Buttà, G. Milio, and G. Licata, "Effects of physical exercise on inflammatory markers of atherosclerosis," Current Pharmaceutical Design, vol. 18, no. 28, pp. 4326-4349, 2012.

[53] P. Correa and M. B. Piazuelo, "The gastric precancerous cascade," Journal of Digestive Diseases, vol. 13, no. 1, pp. 29, 2012.

[54] S. Peters, N. Grunwald, P. Rümmele et al., "Chronic psychosocial stress increases the risk for inflammation-related colon carcinogenesis in male mice," Stress, vol. 15, no. 4, pp. 403-415, 2012.

[55] L. A. Cox Jr, "Dose-response thresholds for progressive diseases," Dose Response, vol. 10, no. 2, pp. 233-250, 2012.

[56] A. Lindberg, L. G. Larsson, E. Rönmark, and B. Lundbäck, "Co-morbidity in mild-to-moderate COPD: comparison to normal and restrictive lung function," Chronic Obstructive Pulmonary Disease, vol. 8, no. 6, pp. 421-428, 2011.

[57] N. H. T. ten Hacken, "Physical inactivity and obesity: relation to asthma and chronic obstructive pulmonary disease?" Proceedings of the American Thoracic Society, vol. 6, no. 8, pp. 663-667, 2009.

[58] E. F. M. Wouters, N. L. Reynaert, M. A. Dentener, and J. H. J. Vernooy, "Systemic and local inflammation in asthma and chronic obstructive pulmonary disease is there a connection?" Proceedings of the American Thoracic Society, vol. 6, no. 8, pp. 638-647, 2009.

[59] C. M. Chang, C. J. Hsieh, J. C. Huang, and I. C. Huang, "Acute and chronic fluctuations in blood glucose levels can increase oxidative stress in type 2 diabetes mellitus," Acta Diabetologica, vol. 49, no. 1 Supplement, pp. 171-177, 2012.

[60] B. C. van Bussel, S. S. Soedamah-Muthu, R. M. Henry et al., "EURODIAB Prospective Complications Study Group, Unhealthy dietary patterns associated with inflammation and endothelial dysfunction in type 1 diabetes: The EURODIAB study," Nutrition and Metabolism in Cardiovascular Disease. In press. 
[61] D. Kadetoff, J. Lampa, M. Westman, M. Andersson, and E. Kosek, "Evidence of central inflammation in fibromyalgiaincreased cerebrospinal fluid interleukin-8 levels," Journal of Neuroimmunology, vol. 242, no. 1-2, pp. 33-38, 2012.

[62] E. Ortega, M. E. Bote, E. Giraldo, and J. J. García, "Aquatic exercise improves the monocyte pro- and anti-inflammatory cytokine production balance in fibromyalgia patients," Scandinavian Journal of Medical Science and Sports, vol. 22, no. 1, pp. 104-112, 2012.

[63] A. Berni, E. Ciani, M. Bernetti et al., "Renal resistive index and low-grade inflammation in patients with essential hypertension," Journal of Human Hypertension, vol. 26, no. 12, pp. 723-730, 2012.

[64] H. He, Z. Zhao, J. Chen et al., "Metformin-based treatment for obesity-related hypertension: a randomized, doubleblind, placebo-controlled trial," Journal of Hypertension, vol. 30, no. 7, pp. 1430-1439, 2012.

[65] F. Sari, E. Eray, and R. Sari, “The effect of quinapril treatment on insulin resistance, leptin and high sensitive C-reactive protein in hypertensive patients," Clinical Experimental Hypertension, vol. 33, no. 8, pp. 548-551, 2011.

[66] T. Sugiura, Y. Dohi, S. Yamashita et al., "Impact of lipid profile and high blood pressure on endothelial damage," Journal of Clinical Lipidology, vol. 5, no. 6, pp. 460-466, 2011.

[67] M. K. Piya, P. G. McTeman, and S. Kumar, "Adipokine inflammation and insulin resistance: the role of glucose, lipids and endotoxin," Journal of Endocrinology. In press.

[68] S. E. Shoelson, J. Lee, and A. B. Goldfine, "Inflammation and insulin resistance," Journal of Clinical Investigation, vol. 116, no. 7, pp. 1793-1801, 2006.

[69] D. I. Simon, "Inflammation and vascular injury," Circulation Journal, vol. 76, no. 8, pp. 1811-1818, 2012.

[70] A. P. Kalogeropoulos, V. V. Georgiopoulou, and J. Butler, "From risk factors to structural heart disease: the role of inflammation," Heart Fail Clinics, vol. 8, no. 1, pp. 113-123, 2012.

[71] E. Vizzardi, I. Bonadei, B. Piovanelli et al., "Helicobacter pylori and ischemic heart disease," Panminerva Medica, vol. 53, no. 3, pp. 193-202, 2011.

[72] H. T. Kang, J. K. Kim, J. Y. Shim, H. R. Lee, J. A. Linton, and Y. J. Lee, "Low-grade inflammation, metabolic syndrome and the risk of chronic kidney disease: the 2005 Korean national health and nutrition examination survey," Journal of Korean Medical Science, vol. 27, no. 6, pp. 630-635, 2012.

[73] I. Kocyigit, M. G. Kaya, O. Orscelik et al., "Early arterial stiffness and inflammatory bio-markers in normotensive polycystic kidney disease patients," American Journal of Nephrology, vol. 36, no. 1, pp. 11-18, 2012.

[74] D. Luis-Rodríguez, A. Martínez-Castelao, J. L. Górriz, F. DeÁlvaro, and J. F. Navarro-González, "Pathophysiological role and therapeutic implications of inflammation in diabetic nephropathy," World Journal of Diabetes, vol. 3, no. 1, pp. 7$18,2012$.

[75] J. Tang, H. Yan, and S. Zhuang, "Inflammation and oxidative stress in obesity-related glomerulopathy," International Journal of Nephrology, vol. 2012, Article ID 608397, 11 pages, 2012.

[76] M. Hulsmans, B. Geeraert, D. De Keyzer et al., "Interleukin-1 receptor-associated kinase- 3 is a key inhibitor of inflammation in obesity and metabolic syndrome," PLoS One, vol. 7, no. 1, Article ID e30414, 2012.

[77] M. G. Rico-Rosillo and G. B. Vega-Robledo, "New trends in macrophages, inflammation and adipose tissue," Revista
Médica del Instituto Mexicano del Seguro Social, vol. 50, no. 1, pp. 39-45, 2012.

[78] R. Stienstra, C. Duval, M. Müller, and S. Kersten, "PPARs, obesity, and inflammation," PPAR Research, Article ID 95974, 2007.

[79] N. Tajik, S. A. Keshavarz, F. Masoudkabir et al., "Effect of diet-induced weight loss on inflammatory cytokines in obese women," Journal of Endocrinological Investigations. In press.

[80] E. Gremese and G. Ferraccioli, "The metabolic syndrome: the crossroads between rheumatoid arthritis and cardiovascular risk," Autoimmunity Reviews, vol. 10, no. 10, pp. 582-589, 2011.

[81] M. Prete, V. Racanelli, L. Digiglio, A. Vacca, F. Dammacco, and F. Perosa, "Extra-articular manifestations of rheumatoid arthritis: an update," Autoimmunology Review, vol. 11, no. 2, pp. 123-131, 2011.

[82] A. Denes, E. Pinteaux, N. J. Rothwell, and S. M. Allan, "Interleukin-1 and stroke: biomarker, harbinger of damage, and therapeutic target," Cerebrovascular Disease, vol. 32, no. 6, pp. 517-527, 2011.

[83] C. W. Wu, P. Z. Chao, W. R. Hao, T. H. Liou, and H. W. Lin, "Risk of stroke among patients with rhinosinusitis: a population-based study in Taiwan," American Journal of Rhinological Allergy, vol. 26, no. 4, pp. 278-282, 2012.

[84] A. Powell, A. J. Teichtahl, A. E. Wluka, and F. M. Cicuttini, "Obesity: a preventable risk factor for large joint osteoarthritis which may act through biomechanical factors," British Journal of Sports Medicine, vol. 39, no. 1, pp. 4-5, 2005.

[85] L. Beck, Foods that Fight Disease. A Nutrition Guide for Staying Healthy for Life, Penguin Canada, Toronto, Canada, 2010.

[86] J. Daniluk, Meals that Heal Inflammation. Embrace Healthy Living and Eliminate Pain, One Meal at a Time, Random House Canada, Toronto, Canada, 2011.

[87] A. W. Weil, Anti Inflammatory Diet and Pyramid, http:// www.drweil.com/drw/u/ART02012/anti-inflammatory-diet, 2012.

[88] Meeting the challenge of living well at a glance 2012, Centers for Disease Control and Prevention, http://www.cdc.gov/chronicdisease/resources/publications/ AAG/arthritis.htm, 2012.

[89] B. E. Wisse, "The inflammatory syndrome: the role of adipose tissue cytokines in metabolic disorders linked to obesity," Journal of the American Society of Nephrology, vol. 15, no. 11, pp. 2792-2800, 2004.

[90] R. Liu, N. Wei, W. Guo et al., "Octreotide alleviates obesity by reducing intestinal glucose absorption and inhibiting lowgrade inflammation," European Journal of Nutrition. In press.

[91] E. Dean, "Physical therapy in the 21st century (Part II): evidence-based practice within the context of evidenceinformed practice," Physiotherapy Theory and Practice, vol. 25, no. 5-6, pp. 354-368, 2009.

[92] W. Frerichs, E. Kaltenbacher, J. P. van de Leur, and E. Dean, "Can physical therapists counsel patients with lifestylerelated health conditions effectively? A systematic review and implications," Physiotherapy Theory and Practice, vol. 28, no. 8, pp. 571-587, 2012.

[93] World Health Organization, International Classification of Functioning, Disability and Health, http://www.sustainabledesign.ie/arch/ICIDH-2PFDec-2000.pdf, 2002.

[94] S. Hasson, "Editorial-special issue 'physical therapy practice in the 21st century: a new evidence-informed paradigm and implications," Physiotherapy Theory and Practice, vol. 25, no. 5-6, pp. 327-462, 2009. 
[95] E. S. Ford, M. M. Bergmann, J. Kröger, A. Schienkiewitz, C. Weikert, and H. Boeing, "Healthy living is the best revenge: findings from the European prospective investigation into cancer and nutrition-potsdam study," Archives of Internal Medicine, vol. 169, no. 15, pp. 1355-1362, 2009.

[96] P. M. Ridker, "High-sensitivity C-reactive protein: potential adjunct for global risk assessment in the primary prevention of cardiovascular disease," Circulation, vol. 103, no. 13, pp. 1813-1818, 2001.

[97] P. M. Ridker, "Clinical application of C-reactive protein for cardiovascular disease detection and prevention," Circulation, vol. 107, no. 3, pp. 363-369, 2003.

[98] P. M. Ridker, M. Cushman, M. J. Stampfer, R. P. Tracy, and C. H. Hennekens, "Inflammation, aspirin, and the risk of cardiovascular disease in apparently healthy men," New England Journal of Medicine, vol. 336, no. 14, pp. 973-979, 1997.

[99] P. M. Ridker, C. H. Hennekens, J. E. Buring, and N. Rifai, “Creactive protein and other markers of inflammation in the prediction of cardiovascular disease in women," New England Journal of Medicine, vol. 342, no. 12, pp. 836-843, 2000.

[100] M. Bodner, R. E. Rhodes, W. C. Miller, and E. Dean, "Smoking cessation and counselling: practices of Canadian physical therapists," American Journal of Preventive Medicine, vol. 43, no. 1, pp. 67-71, 2012.

[101] E. Dean, Z. Li, W. P. Wong, and M. E. Bodner, "Cardiology best practice-effective health education meets biomedical advances: reducing the ultimate knowledge translation gap," in Novel Strategies in Ischemic Heart Disease, U. Lakshmanadoss, Ed., pp. 301-318, InTech Publishing, Rijeka, Croatia, 2012.

[102] R. K. Martins and D. W. McNeil, "Review of Motivational Interviewing in promoting health behaviors," Clinical Psychology Review, vol. 29, no. 4, pp. 283-293, 2009.

[103] “The 5 A's Cycle," World Health Organization, http://www .who.int/diabetesactiononline/about/WHO\%205A\%20ppt .pdf, 2004.

[104] T. van Achterberg, G. G. J. Huisman-De Waal, N. A. B. M. Ketelaar, R. A. Oostendorp, J. E. Jacobs, and H. C. H. Wollersheim, "How to promote healthy behaviours in patients? An overview of evidence for behaviour change techniques," Health Promotion International, vol. 26, no. 2, pp. 148-162, 2011.

[105] L. M. Christian, R. Glaser, K. Porter, W. B. Malarkey, D. Beversdorf, and J. K. Kiecolt-Glaser, "Poorer self-rated health is associated with elevated inflammatory markers among older adults," Psychoneuroendocrinology, vol. 36, no. 10, pp. 1495-1504, 2011.

[106] A. Barr and P. G. Conaghan, "Osteoarthritis: a holistic approach," Clinical Medicine, vol. 12, no. 2, pp. 153-155, 2012. 


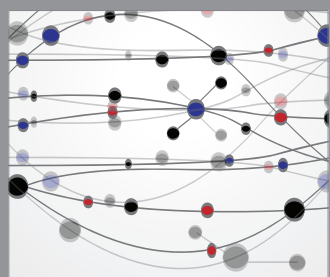

The Scientific World Journal
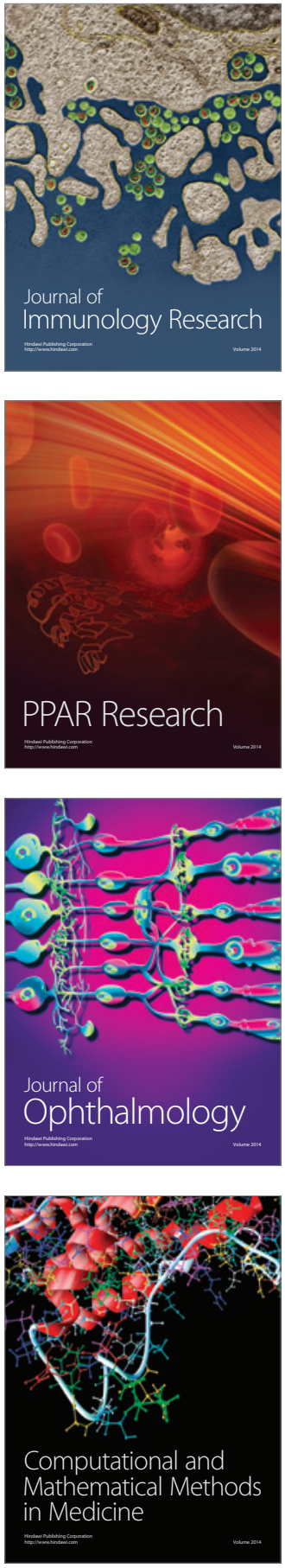

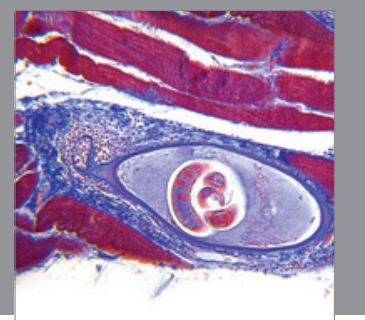

Gastroenterology

Research and Practice
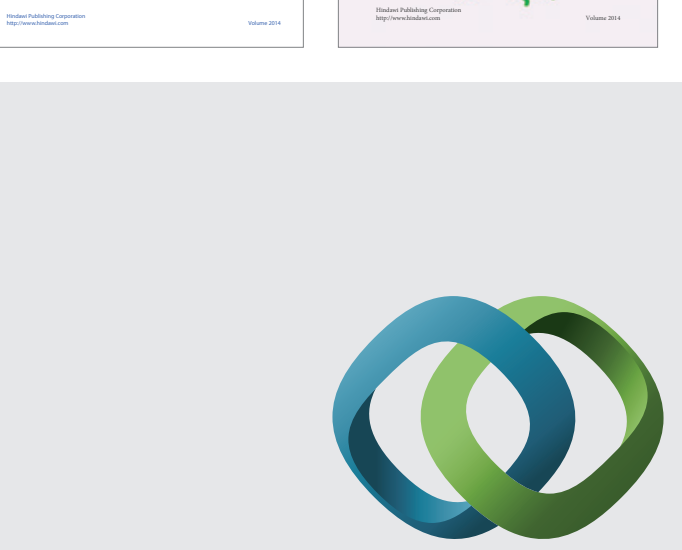

\section{Hindawi}

Submit your manuscripts at

http://www.hindawi.com
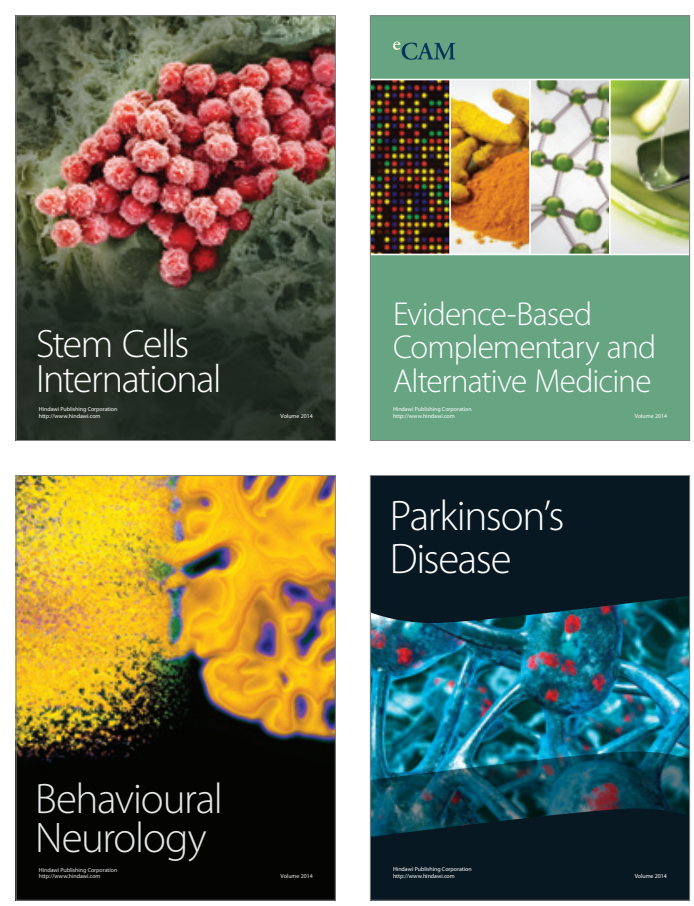

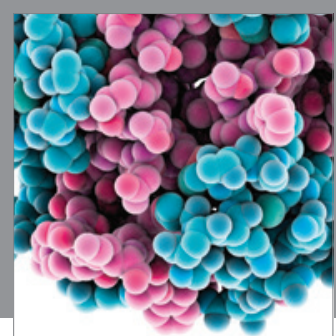

Journal of
Diabetes Research

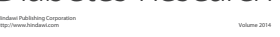

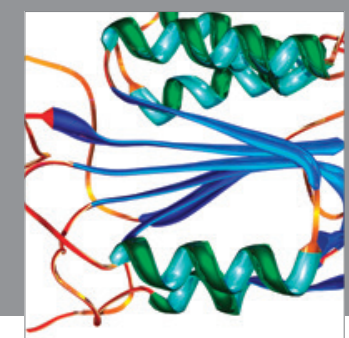

Disease Markers
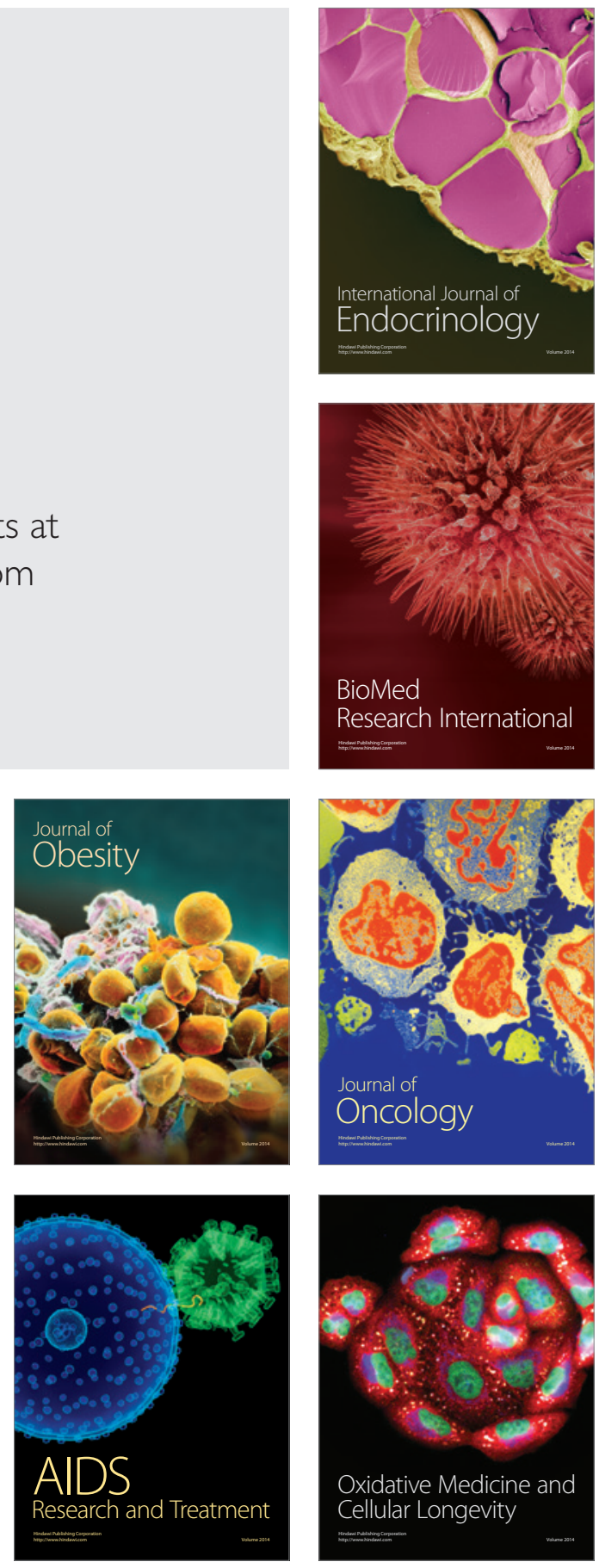